\title{
A FRAMEWORK FOR
}

\section{EUROPEAN CROWDFUNDING}

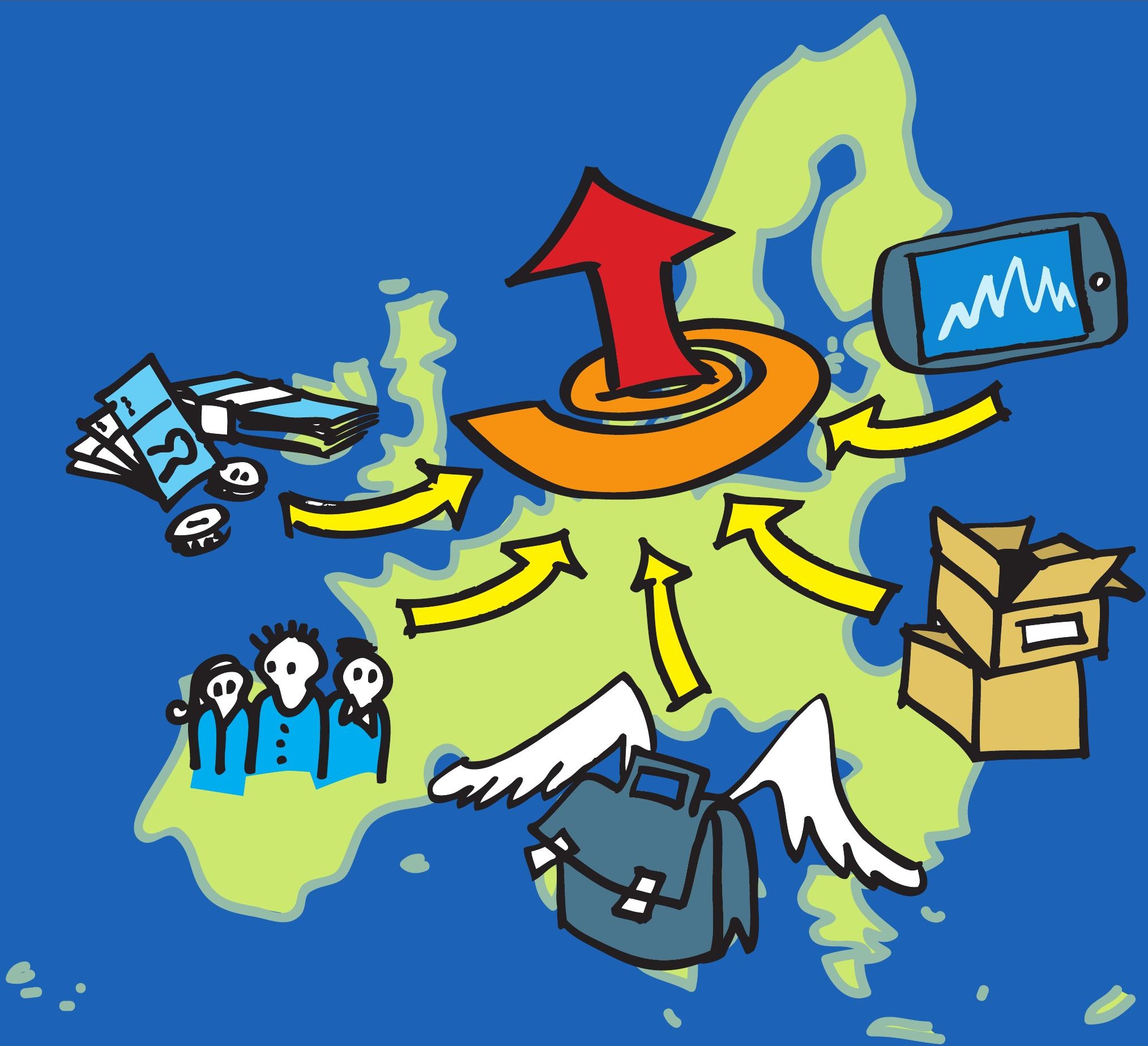

Kristof De Buysere

Oliver GAJDA

Ronald KLEVERLAan

DAN MAROM

WITH A FOREWORD BY

MAtTHias KLAES 


\section{A FRAMEWORK FOR EUROPEAN CROWDFUNDING}

\section{AUTHORS}

Kristof De Buysere

Oliver Gajda

Ronald Kleverlaan

Dan Marom

FOREWORD

Matthias Klaes, Professor of Commerce, Keele University

\section{CONTRIBUTORS}

Alain Renaud

Alexis Wochenmarkt

Alex Raguet

Bart Becks

Clas Beese

Christian Saublens

Emma Fau

Eva Serlachius

Fabien Risterucci

Frederic Baud

Guillaume Desclée

Iwona Mertin

Jamie Hartzell

Karol Król

Katelijn Tailly

Korstiaan Zandvliet

Liam Collins

Lionel Slusny

Pascal De Keyser

Paulo Silva Pereira

Reinhard Willfort

Rhydian Lewis

Robert van Meer

Simone Dean-Johns

Thierry Merquiol

Tim Meuleman

Yann Le Jeune

Yannis Pierrakis
(France)

(Belgium)

(France)

(Belgium)

(Germany)

(Belgium)

(Belgium)

(Finland)

(France)

(France)

(Belgium)

(Belgium)

(Great Britain)

(Poland)

(Belgium)

(The Netherlands)

(Great Britain)

(France)

(Belgium)

(Portugal)

(Austria)

(Great Britain)

(The Netherlands)

(Great Britain)

(France)

(The Netherlands)

(France)

(Great Britain) 


\section{A FRAMEWORK FOR EUROPEAN CROWDFUNDING}

SUPPORTERS

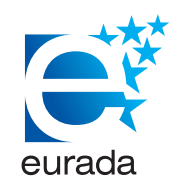

starteed
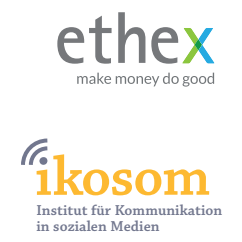

$\frac{\text { iSh } \begin{array}{l}\text { innovation } \\ \text { service } \\ \text { network }\end{array}}{\text { www.innovation.at }}$

Neurovation.net Deine Ideenplattform

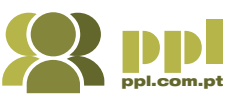

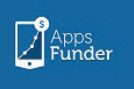

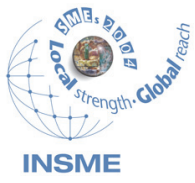

¿ SYMBID growvc

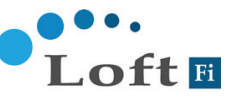

$$
\text { e. EUcapital }
$$

\section{finmar}

$1000 \times 1000$ at

INVESD○R

Twintangibles

\section{Nesta.}

\author{
WISEED \\ $\mathrm{mmi}$
}

\author{
THALES
}

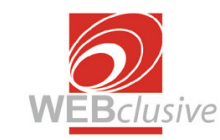

lumogis

angel.me

fashionāngel

filmāngel

Wsonicaingel

\section{IMPRESSUM}

A Framework for European Crowdfunding, 1st ed., 2012

Kristof De Buysere, Oliver Gajda, Ronald Kleverlaan and Dan Marom, with a foreword by Matthias Klaes

This work is licensed under a Creative Commons

Attribution-NonCommercial-ShareAlike 3.0 Unported License.

\section{(c) (7)(2) (2)}

ISBN 978-3-00-040193-0

Layout: www.runtinx.de

Illustrations: Astrid Böckermann

in association with

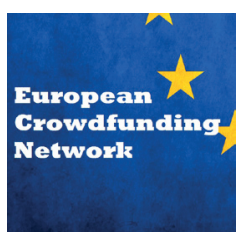




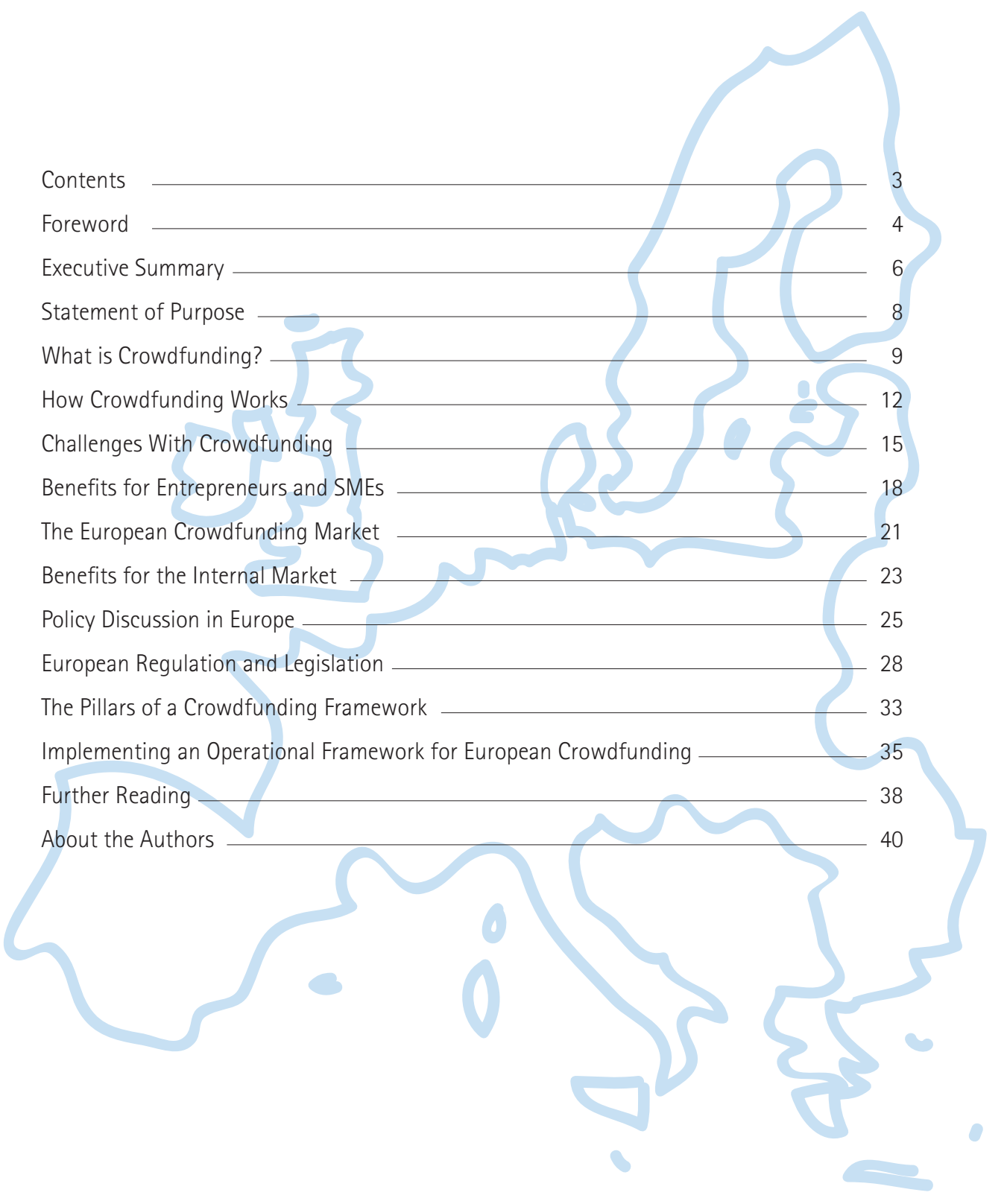


It is more than five years ago now that the first ripples of the current financial crisis started spreading across the globe. What initially looked like a problem largely confined to the North American sub-prime mortgage sector soon affected most advanced economies in the Western hemisphere. In Europe in particular, uncertainties resulting from a general squeeze on retail credit have been acerbated by recurring threats of systemic disruption in the financial and monetary spheres.

Virtually overnight, small and medium sized enterprises have thus found themselves at the sharp end of diminished access to credit. They are joined in their plight by all those organisations and initiatives in the cultural sector who experience a period of almost unprecedented financial restraint, while private households even in good financial standing may struggle to gain access to reasonably priced loans.

The economist Joseph Schumpeter spoke in a similar context of the "gales of creative destruction" unleashed during an economic crisis. New forms of economic activity may gain foothold and begin to disrupt established ways of doing business. Crowdfunding is arguably the most visible instance at present of such a reshaping being under way. As a phenomenon, it prompts us to revise our understanding of and approaches to small to medium scale fundraising across most economic activity.

This report is thus very timely indeed. As the authors describe in comprehensive detail, crowdfunding may take many forms. But it is clear from their survey that we are witness to the rise of a new kind of investor, a new kind of entrepreneur, and a new kind of intermediary, who are all coming together in novel ways of channelling funds to innovative projects and SMEs.

The authors also do not hesitate to point out that crowdfunding, as a disruptive technology of financial intermediation, comes with a set of challenges that policy makers cannot afford to ignore. In its many forms, crowdfunding often straddles boundaries between different regulatory approaches and frameworks to financial intermediation and investing. This is particularly true in a European context where common regulatory approaches to financial intermediation have displayed a marked tendency to lag behind the establishment of the common market itself. Questions have also been raised regarding consumer and investor protection in this context.

As we are gaining a deeper conceptual and empirical understanding of the issues involved, the framework presented here not only seeks to move the discussion along with a number of concrete policy proposals, it also seeks deeper engagement with the various stakeholders. A call for further research is thus one of its key pillars, alongside joined up regulatory thinking and targeted educational initiatives.

In this light, I commend A Framework for European Crowdfunding to your attention. It deserves the widest possible readership and debate, and should facilitate a step-change in approach and coordinated response to what clearly has the potential of turning into a lasting reconfiguration of an increasingly important dimension of financial intermediation in Europe and beyond.

\section{MAtTHias Klaes}

Professor of Commerce, Keele University

Author (with N. Wilkinson) of An Introduction to Behavioral Economics

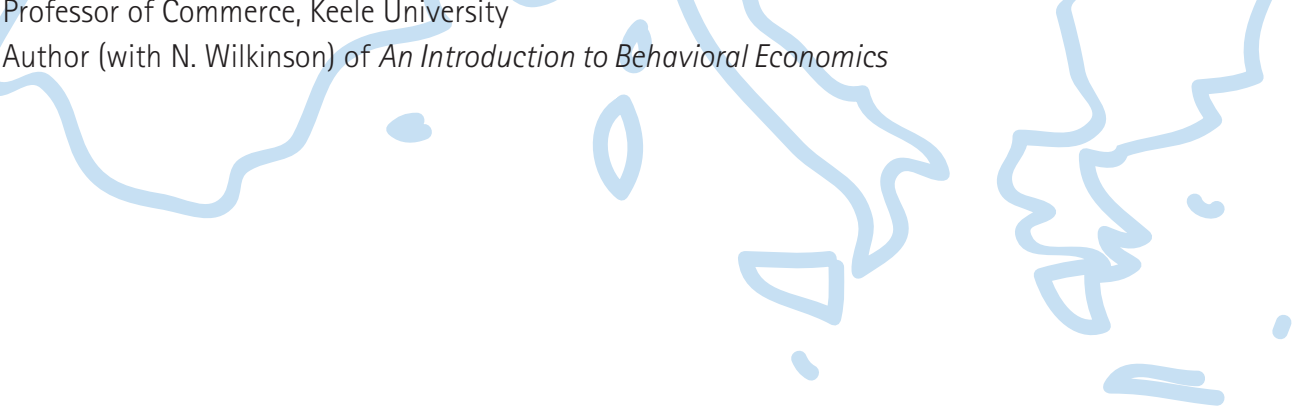




\section{EXECUTIVE SUMmaRY}

\section{爱 \\ "While all our ancient beliefs are tottering and disappearing, while the old pillars of society are giving way one by one, the power of the crowd is the only force that nothing menaces, and of which the pres- tige is continually on the increace. The age we are about to enter will in truth be the era of crowds."}

Gustave Le Bon

This paper is structured to give a concise overview of the state of crowdfunding in Europe, with the aim of establishing policy and a distinct framework for the European crowdfunding industry, efforts which we believe will aid in the economic recovery of Europe.

Research shows the majority of job creation comes from small and medium sized businesses, which account for $99 \%$ of all businesses in Europe. The vast majority of these have ten or fewer employees.

These are also the businesses that have been most impacted by the economic crisis, and as such, need better access to capital in order to do what they do best: innovate, create jobs, and restore stability.

One of the most promising solutions for restoring capital to entrepreneurs and SME is crowdfunding, defined as the collective effort of individuals who network and pool their resources, usually via the Internet, to support efforts initiated by other people or organizations.

In its various forms, crowdfunding allows entrepreneurs and SME to solicit capital from funders, using social networks and crowdfunding platforms to finance their businesses and projects.

There is currently no established policy in Europe for crowdfunding and we believe it is of the utmost importance to create crowdfunding legislation to remain competitive in a global market.

Last year, Europe raised around $€ 300$ million or one third of the world market, considering all types of crowdfunding. At the end of 2011, there were around 200 crowdfunding platforms active in Europe. Their number is expected to increase by $50 \%$ by the end of 2012 .

For SMEs and entrepreneurs, not only can crowdfunding provide start-up capital, it espouses several nonfinancial benefits: validation of product features, market segmentation, price and demand, pre-sales and customer feedback as well as word-of-mouth marketing and a stable, committed shareholding structure.

The European Commission stated its aim to support the business environment for SME's and promote successful entrepreneurship; we believe crowdfunding should be integrated into that aim in the near future. 
To maintain the integrity and proper ethics of crowdfunding in Europe, we believe it is essential to create a framework of best practices and suggest a three pillar approach.

$\rightarrow$ The first pillar is regulation; until legislation is enacted, crowdfunding intermediaries should establish criteria focusing on the following categories of consumer protection: operational and financial transparency practice, financial control, security of information and payments, platform functionality, and operational procedures. These will assist in fraud prevention and detection and will signal credibility to individual funders.

$\rightarrow$ The second pillar is education; for crowdfunding to flourish, we believe a pan-European educational forum is necessary to educate stakeholders, funders, and entrepreneurs on the benefits of the industry, and the different business models of crowdfunding. These forums will provide a reasonable and fair guide to protect the financial interest, exposure and diversification of funders and investees across multiple crowdfunding business models. This needs to provide guidance around fraud, risk explanations and potentially the testing of funders' knowledge.

$\rightarrow$ The third pillar is research; we believe the industry should drive academic and third party research. We believe crowdfunding operators should provide data sets to further industry research; the industry needs to find a transparent and open approach. Public reporting and research will drive competition and innovation within the industry.

Finally, European, national and local legislators and policy makers should join forces to establish crowdfunding-enabling legislation in Europe.

In this paper, we outline a number of potential policies and regulations which we believe offer a good starting point for a broader discussion.

We hope to see many of these thoughts adopted for the benefit of the European economy.

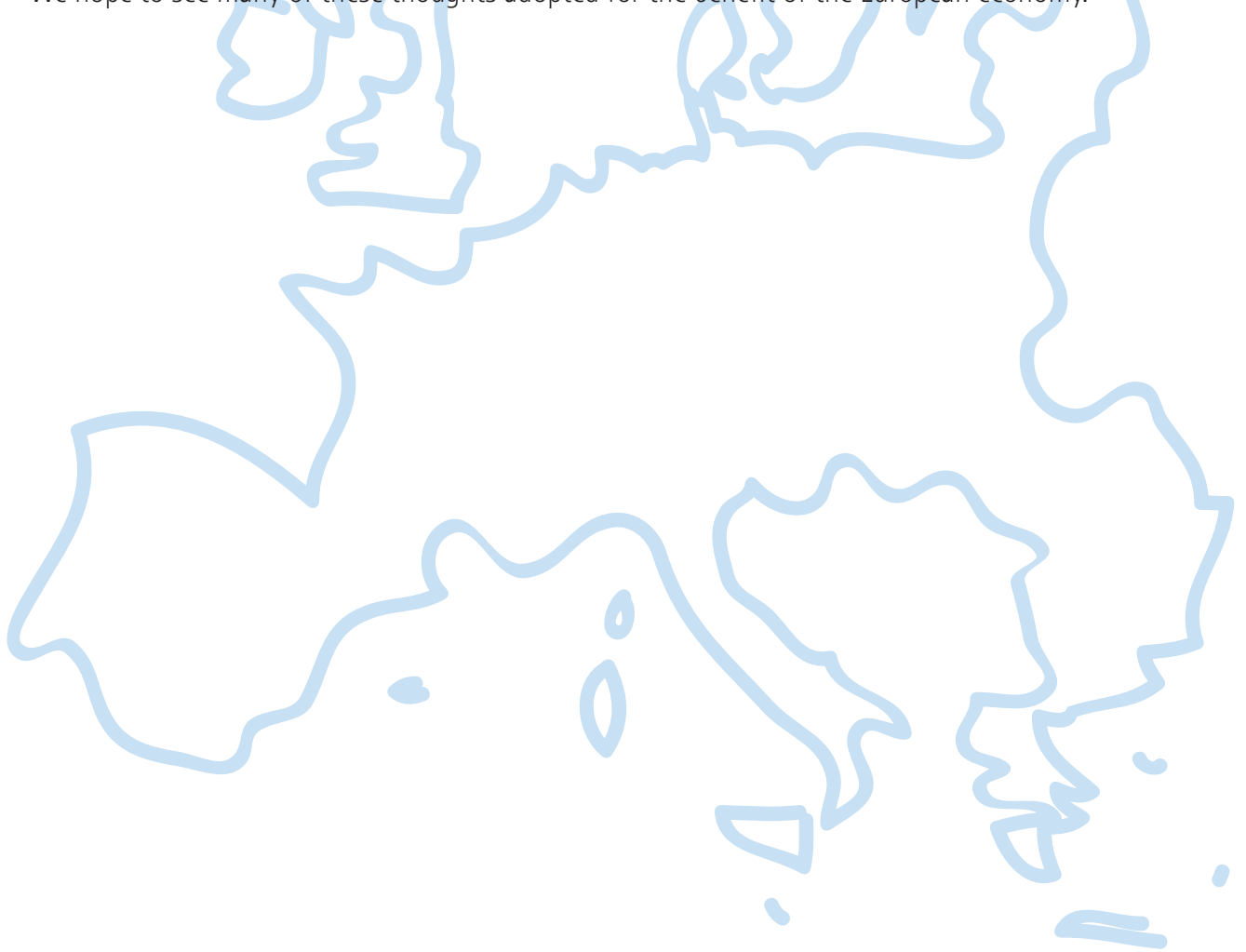




\section{Statement of Purpose}

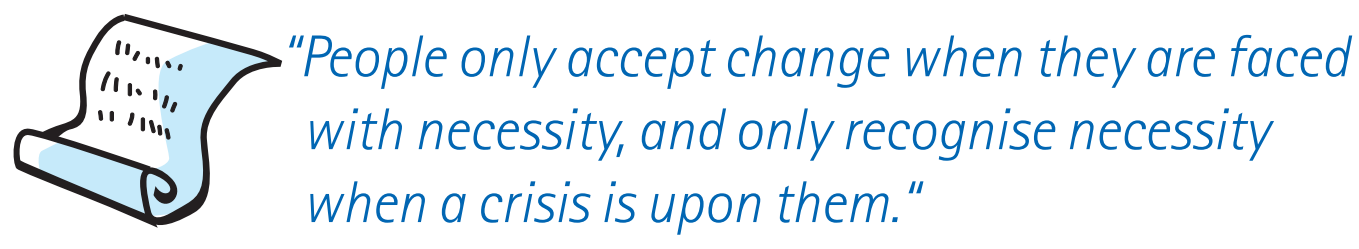

JeAn MONnet

The 2008 financial crisis crippled the global economy. For Europe, the recovery has been tenuous, witnessing the lack of confidence in the sustainability of individual nations, and dwindling trust in the financial services and banking industry.

While the strategy for economic recovery has focused on fiscal policy and the banking system, the brunt of the financial burden is placed on small businesses and entrepreneurs. These groups are left without funding for their businesses, without the security of a bank loan, and without access to credit lines from the financial services industry.

To contextualise the gravity of this problem, we would like to point out that the 23 million small and medium sized enterprises (SMEs) in Europe represent 99\% of businesses. Research from the Kauffman Foundation shows for the past 30 years, all net job creation in the USA has taken place in firms less than five years old. As such, access to capital for SMEs is critical for sparking job creation in Europe.

The European Commission aims to promote successful entrepreneurship and improve the business environment for SMEs. Yet new taxation for banks at the national level and Basel III regulation will likely result in lower lending to SMEs. Venture capital, a sector defined by an anti-cyclical business model with built-in protection from economic crises, is suffering from a serious decline in funds.

Moreover, declining stock prices continue to hinder initial public offerings, ultimately causing venture capitalists to exit investments through trade sales to large or multinational corporations, acts which inhibit exponential growth and job-creation within the start-up community.

The broken glass theory espouses that fixing the small things will help solve the bigger problems. It is clear that significant economic growth and job creation comes from the myriad of innovating, producing, and servicing entrepreneurs that enrich our daily lives and disrupt the established markets.

While not every small business is going to be a game changer, we must provide the infrastructure and access to funding to enable SMEs to succeed. To eliminate the funding gap for SMEs, we must look to the future and innovate.

It must be the civil and ethical duty of European politicians and citizens to find a solution to the economic crisis. We believe the crisis provides an opportunity for much-needed change. Change, albeit disruptive, if managed well, is a guarantor for innovation.

Today one of the most promising tools to help enable economic growth, job creation, and innovation is crowdfunding. We believe crowdfunding is one of the most viable means of funding new ideas, small business and job creation across Europe. It is a highly democratic tool that is posed to have a disruptive impact on community, start-up and consumer finance by allowing value creation on many levels, not just financial. 


\section{WHAT IS CROWDFUNDING?}

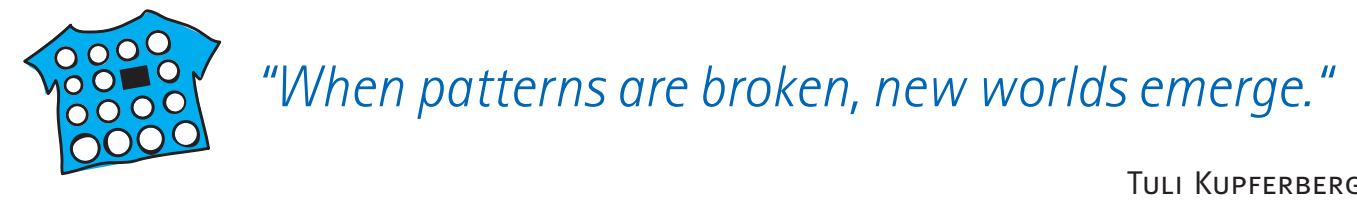

Crowdfunding can be defined as a collective effort of many individuals who network and pool their resources to support efforts initiated by other people or organizations. This is usually done via or with the help of the Internet. Individual projects and businesses are financed with small contributions from a large number of individuals, allowing innovators, entrepreneurs and business owners to utilise their social networks to raise capital.

Common examples of crowdfunding include donations to a charitable cause, a band raising money for an international tour, or even a politician raising money for an election campaign. For example, in 2008, Barack Obama raised \$137 million during his run for the presidency of the United States through an online campaign that showed significant similarities to crowdfunding.

As an industry, crowdfunding is in its infancy. Nearly a decade ago, the first crowdfunding platforms harnessed the internet as a tool for community building and distribution. Yet the basic concept of crowdfunding is much older and has been utilised across disparate industries for decades. Parallels can be identified in community and co-op banking, subscription sales, and the opening of the stock market to retail investors.

The rise of the crowdfunding industry over the past decade comes from the advancement in web and mobile-based web applications and services. Entrepreneurs and businesses can utilise the crowd to obtain ideas, collect money, and solicit input on the product, overall fostering an environment of collective decision-making and allowing businesses to connect with potential customers.

Crowdfunding is used by organisations for market research, financing and marketing. Depending on the need of the project, different business models can be used. The main advantage of crowdfunding is that the funders are also ambassadors of the project or business they support and that they will help to market and promote it through their own networks.

In comparison to incumbent financial services a core difference lies in the funder who participates in crowdfunding. The funder in crowdfunding is usually a somewhat entrepreneurial person, with a certain appetite for excitement, in as much as she or he understands the potential of the project and has the intrinsic urge to be a part of the group that is going to make it happen.

Often, the funder does not own the relevant resources to finance a project in full and also does not own the competencies that may be found in a venture capitalist or financial services expert. Yet the funder usually identifies with the project, has a mind for change, and is happy to help provide the social proof of concept. Important here is a perceived emotional rate of return where the value is not only the probability of future financial gains, but also the engagement in a promising project close to the funders' interests.

Profit maximisation as a goal is rare in crowdfunding, for now. The risk of failure does not necessarily translate into risk of loss of capital, because success is for the funder usually not defined through financial return. 
Of course, the different crowdfunding models also correspond to slightly different motivations in funders, though they all are to some degree intrinsic motivations. There are basically four types of crowdfunding: donation-based, reward- based, equity-based, and lending or debt- based:

$\rightarrow$ Donation: a donor contract without existential reward

$\rightarrow$ Reward: purchase contract for some type of product or service

$\rightarrow$ Lending: credit contract, credit is being repaid plus interest

$\rightarrow$ Equity: shareholding contract, shares, equity-like instruments or revenue sharing in the project/business, potential up-side at exit

\section{CROWDFUnding Business MOdels}

While the terminology stated in the main part of this paper is to some degree widely used in the USA and in Europe, we believe that it does not pay tribute to thriving business model innovations that have been created and thus does not take into account the potential disruptive nature of crowdfunding. We have outlined some of the innovative crowdfunding models in use today separately here.

We believe crowdfunding is transformative in its total of business models, with the biggest potential lying in the combination of different approaches that will allow funding the whole life-cycle of a project, product, services or other business innovation. The following is not meant as an inclusive overview but to showcase variety in crowdfunding business models.

\section{DONATIONS}

NGO's have used this model to attract donations for specific projects for over ten years. Unlike with tradiotional fundrasing, donations are collected and ear-marked for a specific project. Because funders know that their money will be used on a very specific project, they are more willing to donate higher amounts per person.

These types of donors also tend to be more loyal in the long term when the NGO will keep them updated about the progress of the project, ensuring recurring donations. The main motivation for funders is social. It is intrinsic motivation, which is usually a good base for a long term donor relationship.

\section{REWARDS}

This business model is used by project owners who want to collect donations for a specific project and can give (often small) non-financial rewards in return. The rewards are of a symbolic value and provided by the investee. They are usually much lower than the donation amount, to ensure there is enough money left for the project.

Nevertheless, the perception of the value can be much higher, for example special VIP tickets as a reward for a higher donation. A reward in this context should not be understood as a token of appreciation. In general, the parties do not consider it a legally binding obligation to provide the goods and do not classify it as a sale.

When the different reward-levels are chosen wisely, it is possible to receive a much higher average donation than with a pure donation-based approach.

\section{PRE-SALES}

It is possible to put a new product or service online and ask funders if they are interested to order and pay in advance. This replaces traditional market research and validates demand while providing working capital, if successful.

Funders that participate in these crowdfunding campaigns do it because they want this product or service to be made. Another reason is that they will get a discount on the sales price.

\section{LENDING}

With lending-based crowdfunding, a company will borrow money from a group of people instead of a bank. The role of the platform can be diverse. Some of the platforms will act as a middle-man and will also make the repayments to the lenders, where other platforms act only as match-makers and the borrower and lenders will be connected when the deal is closed.

\section{SOCIAL LENDING}

Some platforms give the possibility to lend to social projects with no interest being offered, for example where businesses in developing countries can receive micro-financing without any interest being paid to the lending party. 


\section{PeER-To-PeER Lending}

Although Peer-to-Peer Lending (P2P) is not "real" crowdfunding and is not necessarily based on goodwill, it is an interesting new financing model for loans. It has some characteristics of crowdfunding lending, but the main difference is that the lenders and borrowers usually do not know each other.

With P2P lending, the main motivation for the funder is a (higher) financial return. The interest-rates in general are based on the risk-factor. The risk-factor is calculated based on financial data and personal securities. These calculations are currently done by P2P-platforms that show-case the loans or by independent institutes. There are also innovative models in which the risk is borne by provision funds and not the individual lenders.

This model is used by borrowers who are looking for a loan with a lower interest rate than the one they can get from a bank. It can also be used by borrowers who can offer fewer securities. Existing data shows that default rates for P2P lending on average are very low, below $1 \%$. This subset of crowdfunding is continuously growing and profitable. New lending is estimated at well above $€ 20$ million per month for Europe.

In P2P lending only the money provided by the funders is being lent out. Therefore there is no money creation within the platforms unlike with traditional banks. As a result, there is no systemic risk attached to P2P lending.

\section{PeER-TO-BUsiness Lending}

Similar to P2P lending, there are platforms that provide loans to small and medium sized businesses.

\section{EQUITY CROWDFUNDING}

When a company wants to attract an investment from a group of people, instead of funding by a business angel or another private investor, this is called equity crowdfunding or crowdinvesting.

Some funders are primarily interested in investing in projects that share their own values, that are locally engaging, or that create jobs in their community. Others have a real knowledge of what the market, project, or company is addressing and desires to bring funds and expertise to the success of the project. This practice is very similar to business angels.

Equity crowdfunding also generally includes equity-like arrangements, offering the same payoff as equity (shares), and where the "funder" is actually merely a creditor who has a contractual right to receive that payoff.

\section{VARIATIONS ON THESE MODELS}

Next to the established models which are mentioned above, there are some variations on these models that can be used.

\section{REVEnUe SHARING}

Funders can also receive a return based on future revenues of the company via revenue sharing arrangements for instance or royalty-based financing. Such rare but nonetheless promising alternative payoff structures may be less straightforward to categorise under the notions above, but contractual freedom may allow offering payoff structures that do not resemble equity, equity-like or typical fixed loan payoffs.

\section{IN KIND (REWARD)}

Independent of the type of business model chosen, organizations can give a payoff in kind. This means that based on a monetary input, the funder will receive a payoff in kind that has substantial worth. The exact amount is not always clear at the start of the project, and is thus subject to the risk. Normally these are products or services from that organization.

\section{IN KIND (FUNDING)}

It is also possible to participate in a crowdfunding project as a funder by offering products or services instead of money. In most cases, these products or services otherwise need to be purchased by the project and therefore have a real financial value to the investee. For the funder, the cost of the investment is restricted to opportunity and operating costs.

\section{HYBRID MODELS}

Combined models are also possible. Some platforms experiment with a combined model of loans and pre-sales. A percentage of the funding will be put into a loan (and will be repaid with interest) and the other part of the funding will be used to prefinance the production of the product or service. Also for the entrepreneur there are benefits in hybrid models or in approaches to mix crowdfunding with other investment forms, for example where crowdfunding is used to pre-sell a product, through which market validation and segmentation can be done, to generate revenue and positioning the project for follow-up or parallel investment from business angels. 


\section{HOW CROWDFUnding WORKS}

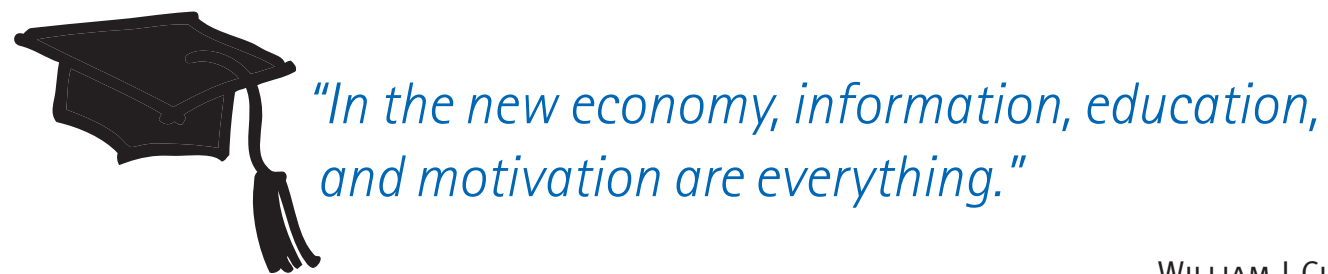

WiLLIAM J CLINTON

Crowdfunding is based on the fact that people want to help other people and projects they like and that are close to them, emotionally or geographically.

Some people are primarily interested in investing in projects that share their own values, that are locally engaging, or that create jobs in their community. Others have a real knowledge of the market a project or company is addressing and desire to bring funds and expertise to the success of the project, very similar to business angels and venture capital funds.

In crowdfunding the actors are project owners (entrepreneurs or individuals with a specific goal), funders (investors, lenders or donors) and the crowdfunding platforms as an intermediary.

\section{MOTIVATION OF FUNDERS}

There are three different motivations for people who want to participate in crowdfunding: social return, material return and financial return.

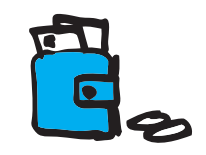

Financial

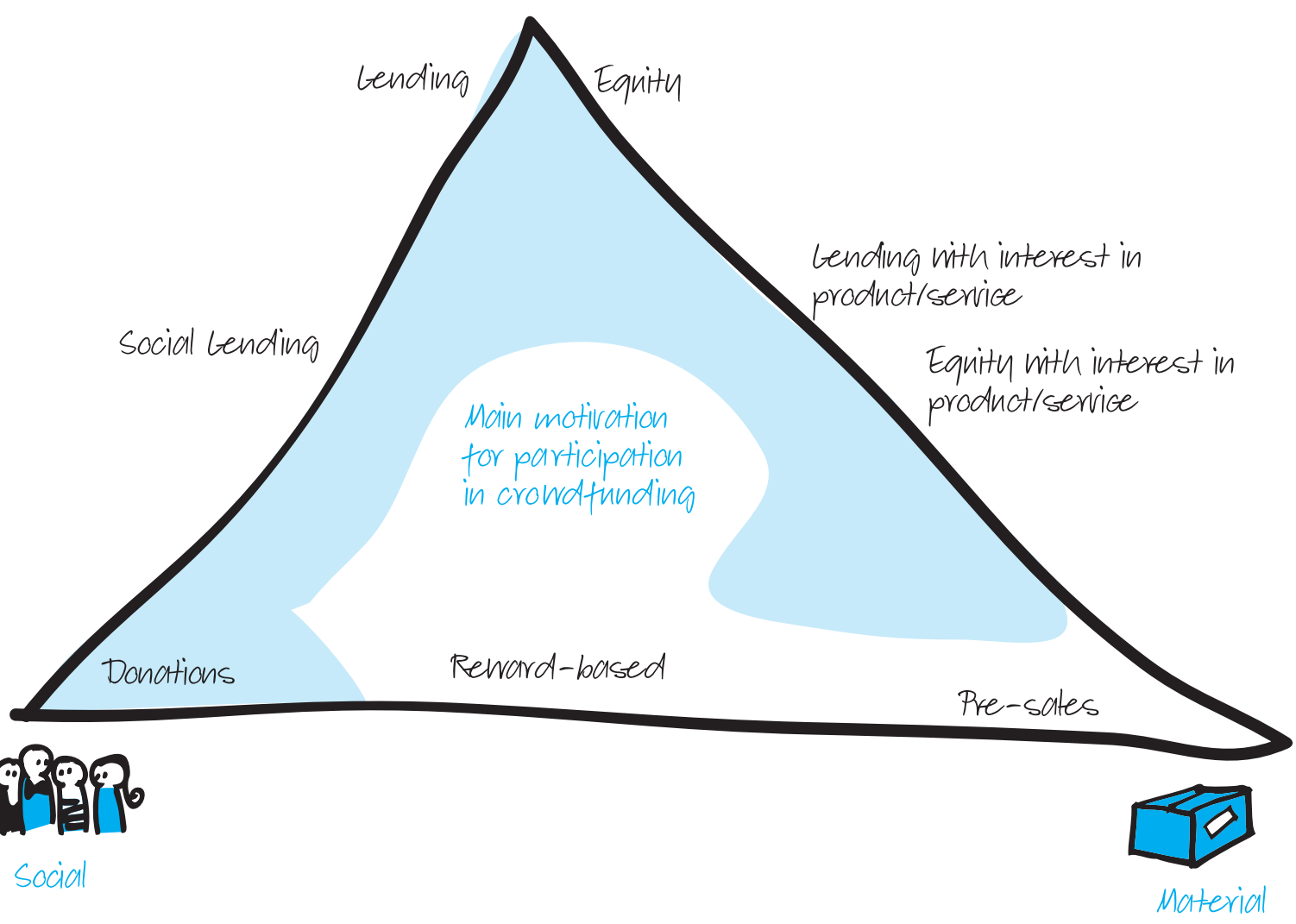




\section{SOCIAL RETURN}

With social return, the funders are already satisfied when they see that a project can be realised, their motivation is intrinsic. Funders do not want anything else in return. This kind of return is normally present with donation-based crowdfunding and is used extensively by non-profit organisations.

\section{Material Return}

With material return, the funders get a product or service as a reward for their investment. The business model that is used for this is pre-sales crowdfunding. An investor pays the project owner in advance. The project owner can use the funds as working capital to create the product or service.

Sometimes a funder is satisfied with a return with a (much) lower economic value than the original investment. This business model is called reward-based crowdfunding. The perceived value can be much higher than the actual economic value, for example, entrance tickets for a concert as a reward for a high donation or a personal meeting with the musicians when a funder gives an even higher donation. Examples are numerous and not limited to any specific industry.

Sometimes material returns are also given to funders in loan and equity-based business models. Here the funders get a product or service from the company they invested in, instead of an interest or dividend payment.

\section{FinANCIAL RetURn}

If a funder likes a crowdfunding idea, but also wants some financial return, he can invest via loan or equitybased crowdfunding. Here the risk is usually diversified between financial and emotional motivations. The project owner can use loans or equity-based crowdfunding to collect investments against interest or dividend payments. In comparison, social lending offers the funder a $0 \%$ interest-rate on his loan.

\section{MOTIVATION OF PROJECT OWNERS}

Besides raising money, crowdfunding allows the project owner to gain feedback on some of the most critical parts of the product before its release into the public marketplace.

For example, the project owner is able to gauge pricing information, demand for the product, feedback on how design might be improved, demographic on potential buyers, precise information about market demands, and direct customer interaction. It can also lead to word-of-mouth recommendation and other social marketing.

For the project owner, crowdfunding establishes a direct link between himself and the customer. This link is the first step towards marketing, customer loyalty, participation, and emotional attachment to the product.

Crowdfunding is an incredibly effective way of gauging if their product or idea has a mass appeal. Even more important is the time in which the project owner is able to make this assessment; a two-month long crowdfunding campaign is a relatively fast turnaround for getting an idea off the ground.

For project owners who experienced a successful crowdfunding campaign for their first round of financing, the aforementioned benefits can be extremely useful for a second round of financing. Some project owners may utilise crowdfunding again, where others may resort to more traditional forms of investment, like venture capital or business angel investing. 
When project owners combine different approaches they can fund the whole life-cycle of a project, product, services or other business innovation.

Either way, being able to call upon pre-sales information, number of funders, amount of money raised in a specific time period is valuable for project owners seeking a second round of financing.

\section{HOW CROWDFUNDING PLATFORMS WORK}

An online platform usually serves as an intermediary between the project owner (entrepreneur or individual) and funder. Below is a simplified sketch of how a typical crowdfunding scheme works:

$\rightarrow$ Online platforms receive applications from project owners who intend to showcase their business idea or cause on the platform's website. Some platforms make a pre-selection of the ideas based on their own criteria, while others automatically publish every idea. Platforms that use pre-selection are checking the background of the project owner and do a quick review on the feasibility of the crowdfunding plan.

$\rightarrow$ After an idea is accepted by the online platform, the project owner is tasked with creating a funding goal over a marked period of time and an online "pitch" (most of the times in the form of a video), where the project owner pitches his/her idea to potential funders. Project owners often utilise social networks to access potential funders on a larger scale. Funders then fund the campaign directly through the online crowdfunding platform.

$\rightarrow$ During the campaign the project owner will keep his funders/fans updated about the process with updates on the online platform.

$\rightarrow$ If the funding goal is reached within the allocated fundraising time frame, the project owner receives the money. If the funding goal is not reached, most of the platforms will reimburse the money to the funders.

$\rightarrow$ In terms of post investment, some funders choose to remain involved in the decision-making and overall strategy of the business. Some funders receive voting rights in the business. In most cases the communication between the funders and project owners will continue through the online platform.

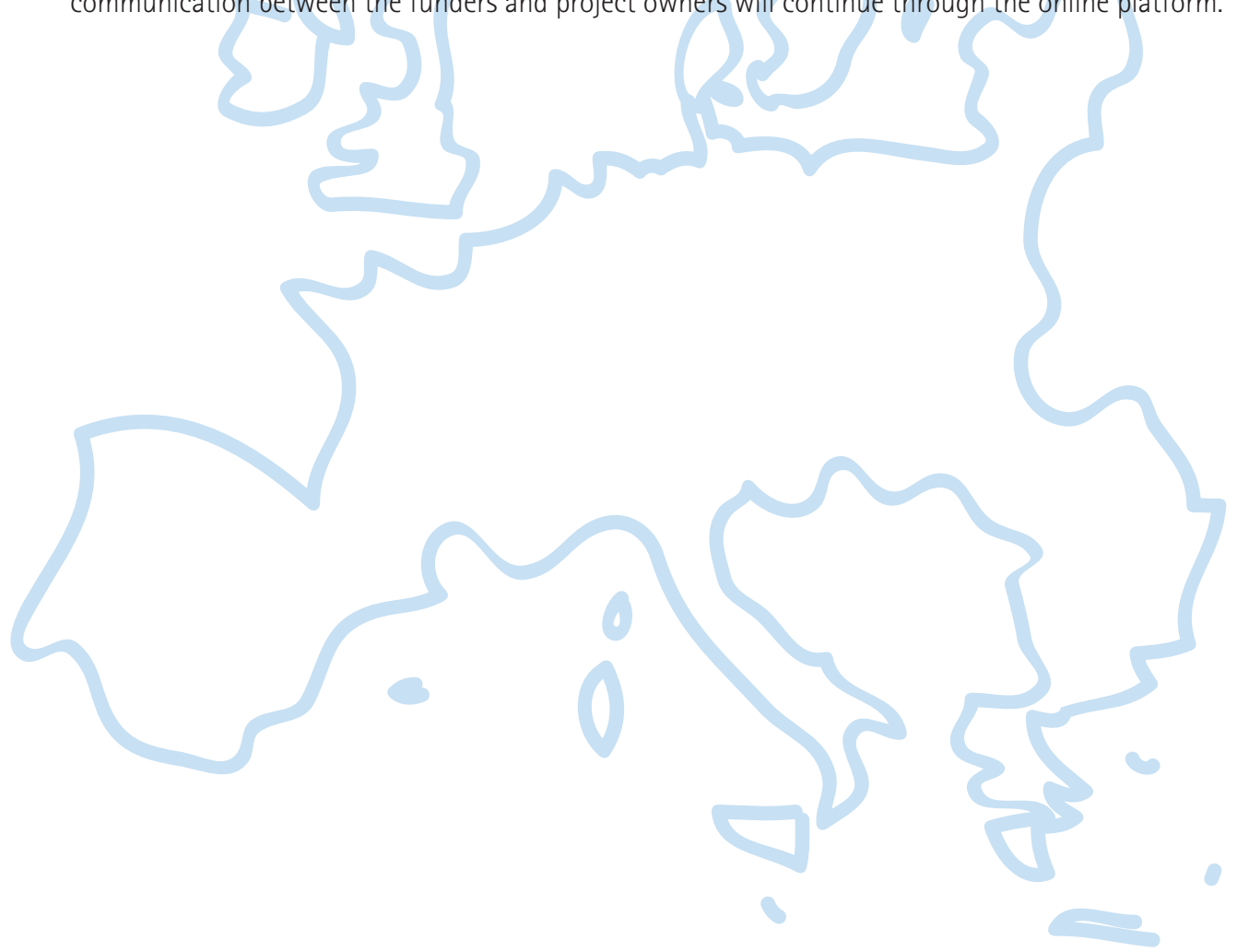




\section{Challenges With CROWDFUNDING}

\section{"We cannot solve our problems with the same thinking we used when we created them."}

Albert Einstein

The following is especially pertinent for, but not limited to, equity-based crowdfunding. There are certain disadvantages in the current approach to crowdfunding that need to be reconciled in the near future. We have outlined below some of the common points of contention below:

\section{FRAUD}

Fraud is perhaps the most widely-debated issue for critics of crowdfunding. Critics point out the potential for funders to fund scams through crowdfunding platforms. The risk for fraud increases in crowdfunding because unlike venture capital or angel investing, the pool of funders has no personal contact or real knowledge of the business idea beyond what is presented on the crowdfunding website.

Moreover, the geographical separation between the business/entrepreneur and funder can prohibit the funder from physically overseeing the business. However, it can also carry advantages in centralised markets. Indeed, fraud prevention and detection is of utmost importance for maintaining the integrity and ethics of the industry. We believe there are several methods of preventing fraud.

First, it is important to note that social media can be used as a tool of fraud prevention. Use of the internet and social networking allows funders to perform research on the entrepreneurs before deciding if they want to invest.

It is also important to look to the crowdfunding platform to vet against fraud. As mentioned before, most crowdfunding websites already have fraud detection mechanisms in place.

Moreover, UK-based independent charity NESTA rightfully points out that the emergence of more crowdfunding platforms will create more competition among platforms, and to remain competitive, fraud detection and vetting services will become even more important.

\section{Setting Valuations}

Another concern with equity crowdfunding is setting valuations so the entrepreneurs can decide how much equity to offer for the amount of capital they want to raise. Current practice establishes that the entrepreneur set the value of the business prior to the start of the crowdfunding campaign.

This can be problematic, particularly as there are often parts of the business, such as intellectual property or estimations on market size and scale that are difficult to estimate or quantify. As such, the

entrepreneur can either undervalue or overvalue the business, creating significant problems for the funders. To circumvent this issue, some crowdfunding platforms permit the entrepreneur to be flexible with the amount of equity offered over the course of the campaign. Another potential solution is allowing the entrepreneur to set the amount of equity and the number of shares, and then call on the potential funders to bid for the equity or shares. Those funders who pay the most money then win the shares/equity. 


\section{Post InVestment Communication}

If a crowdfunding campaign is successful, many funders will continue to be involved in the business at the post-investment stage. Post-investment, funders can provide the entrepreneur with advice on issues ranging from business strategy to product pricing to design.

However, managing a large number of stakeholders, particularly as they may not all be located in the same geographical region, can be incredibly difficult to manage. For the platforms which allot voting power to funders, this can be even more difficult to manage, if not only for purely logistical reasons: imagine allowing 300 disparate funders to vote!

For equity crowdfunding there is also a question about liquidity in the secondary markets, as access to capital, especially equity, for SMEs remains very limited and the possibilities for further funding or exits for the crowd funders are closed. Efforts to combine crowdfunding and business angel investing have been made and are one potential solution, but this will remain a solution for a select few businesses and projects. There is a marked tension between investment and guarding the SMEs that needs to be addressed and resolved in the near future. In this paper, we will address the need for the creation of a framework to be adopted by the crowdfunding industry for best practices and to guard against fraud.

\section{Data, Analysis And Risk Mitigation}

One of the main hurdles associated with crowdfunding is its open nature, insofar as individual funders often times have no formal training and may not be equipped to assess the financial risks involved. Effective risk assessment requires the following three things: reliable data, capacity to analyse, ability to mitigate risks.

Reliable Data: At this stage, there is no commonly accepted data model used for presenting investment projects across platforms. While open source accounting data standards do exist, they have not yet been widely adopted by crowdfunding platforms.

There is also no real obligation for founders to provide any sort of controlled data when pitching an investment project. A common body of operating standards will greatly assist this prospect and will bring about the required transparency the crowdfunding industry requires.

Capacity to Analyse: Individuals investing in crowdfunding platforms often are not professional investors and therefore require metrics of their carried risk when investing in any product. The traditional financial industry uses these measures (albeit with mixed success), and crowdfunding has the potential to bridge the gap in investor information by establishing solid and widely accepted risk measures.

Risk Mitigation: Absolute financial risk is a convolution of investment time, type of products, economic context, diversification of investment, and amounts invested compared to total wealth. All these factors play a complex role in defining whether an investment will be successful or not.

While crowdfunding offers opportunities for infinite diversification, it currently fares poorly in terms of controlling products, investment horizon, and the net investment capacity of individuals. The industry should look to develop a title of "qualified investor in crowdfunding," that should be complemented by the obligation of platforms to provide sound and widely accepted risk measures. 


\section{CONFLICTS Of INTEREST \& OpERATIONAL RISKS}

Conflicts of interest occur when owners or specific funding providers use privy information to generate systematic superior returns compared to the crowd financing it.

Some platforms operate on a co-investment model, whereby an investment fund completes the investment of crowds or precedes it in the form of seed capital. Many of these platforms have already understood the potential conflicts of interest, therefore following a strict 50/50 rule (between own funds and crowdfunded funds) within a single crowdfunding campaign.

Although this is mostly true with single crowdfunding campaigns, all investors' returns have to be compared on the longer term, and there are few guarantees (or laws) that prevent additional deals to be carried out offline (i.e. outside the crowdfunding platforms).

There are also parties who might get a better investment opportunity than the crowd initially responsible for funding. These types of situations must be strictly avoided and rules should be enforced for raising money online (via the crowdfunding platform) vs. raising money offline (in private deals).

Similarly, while we know that many financial institutions do not publicly disclose the identities or demographics of their shareholders. It is critical to question this practice for the crowdfunding industry.

The limited size of many crowdfunding platforms starting-up supposes a high concentration of ownership within the operating companies. This means the actual operations and development depends on the limited set of resources of its shareholders. Size and shareholder capability are therefore a significant issue for many (growing) crowdfunding platforms.

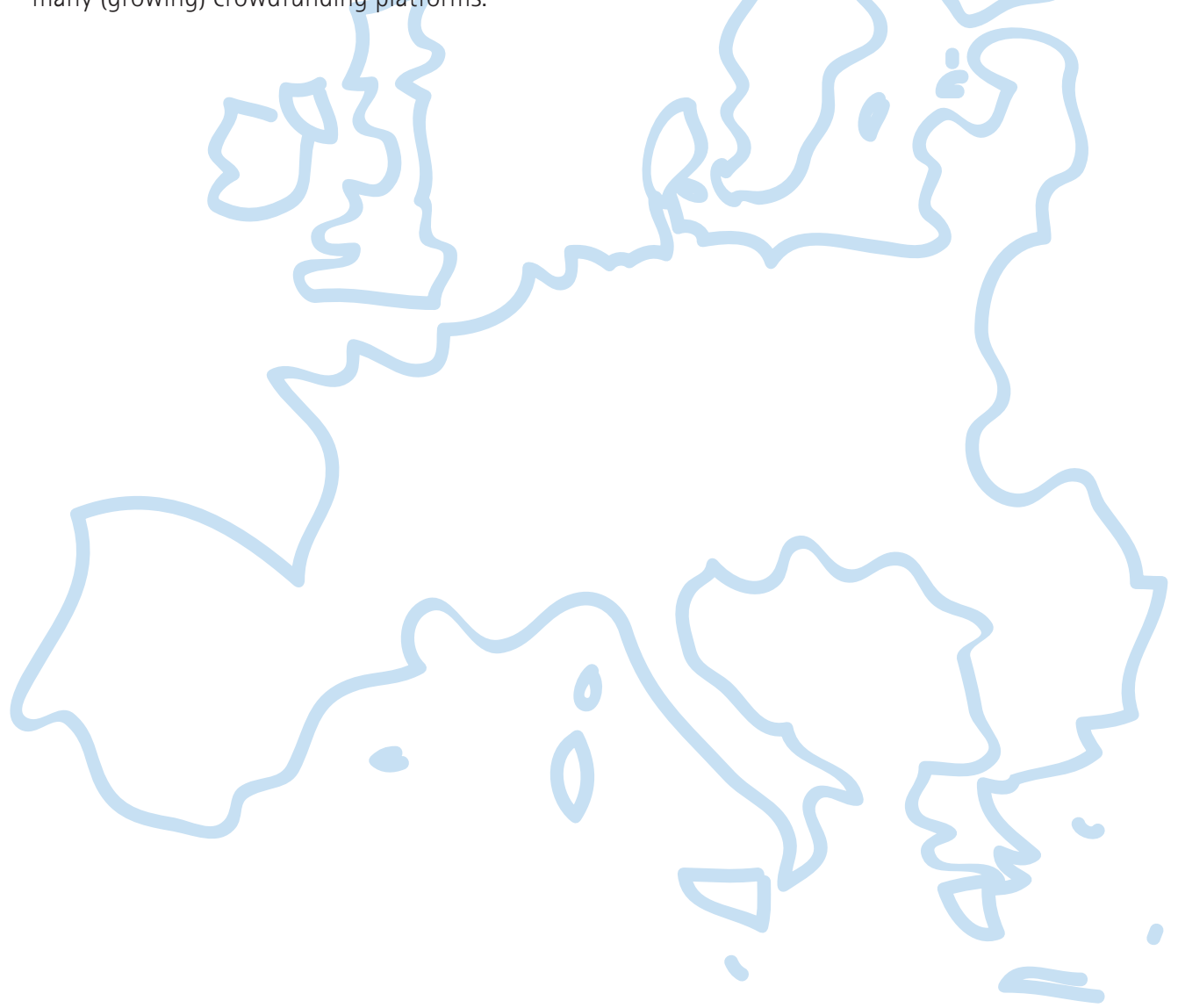




\section{BENEFITS FOR ENTREPRENEURS} AND SMES

Crowdfunding can offer unique support for budding and existing entrepreneurs on multiple levels. No other investment form, be it debt or equity, can provide the benefits of pre-sales, market research, word-of-mouth promotion, and crowd wisdom without additional cost.

Donation-based crowdfunding helps not-for profit organisations to fund projects and core costs, but it can also help to fund creative activities and common purpose activities. Both debt-based crowdfunding and peer-to-peer funding help smooth consumption and income fluctuations, and can provide SMEs funds for business expansion, production, and other activities. This is a compelling alternative to traditional lending products.

Reward-based crowdfunding is frequently used for creative businesses or smaller consumer products, where basic pre-financing for production is linked to an initial demand-test. If a sufficient number of people enter into a funding agreement, the entrepreneur has market validation as well as the pre-financing for his activities.

And finally, equity-based crowdfunding offers an additional route to raise equity for any business venture, with all associated risks. Due to information asymmetries and lack of publicly available data in the traditional sense, the investment risk appears higher. However, through the nature of peer review and peer recommendation, as well as instant feedback and the publication of all necessary project details to a large group of potential funders, some of this risk can be mitigated.

\section{The Early-Stage Equity Investment Ecosystem}

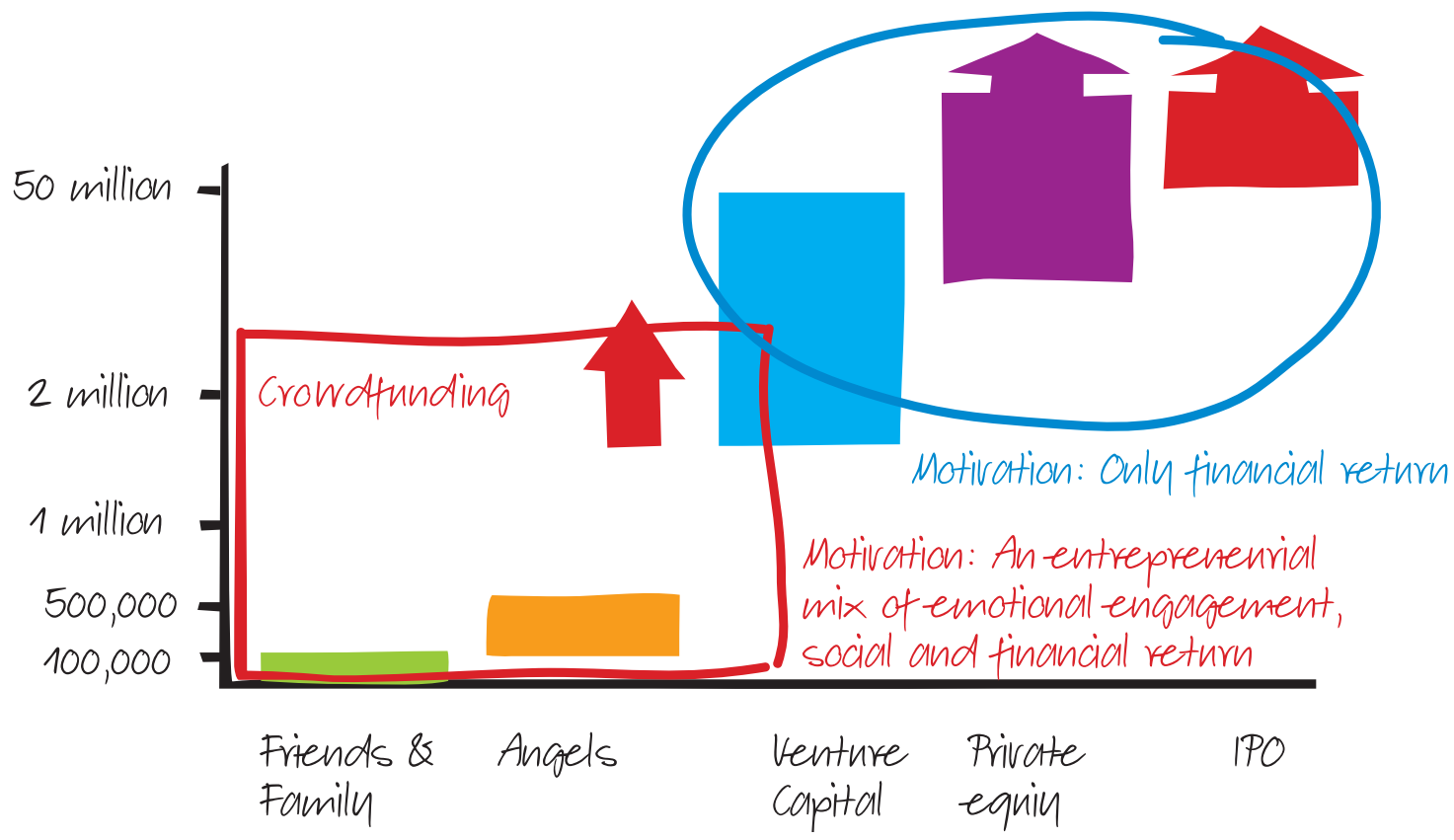


Crowdfunding denotes space for co-creation and the involvement of the end-user in the product definition, a greater pool of innovative ideas and a free word-of-mouth marketing channel. It is also an investment channel for collective wisdom, replacing investment decisions by individual investors or individual fund managers acting based on their personal understanding of or experience with any given market.

These benefits can decrease the cost of product development and pre-marketing, while at the same time generating revenues before production, therefore providing, at best, a positive cash-flow from the start.

Crowdfunding, in all its varieties, is an unparalleled source of pre-seed and seed capital, loans, revenue and donations. Crowdfunding has the real opportunity to apply leverage where all other formal financial services fail.

In the very early, pre-seed stages that are usually fully financed by the entrepreneurs themselves, their families and their friends, crowdfunding can provide risk-diversification to start-up and micro-entrepreneurs in highly innovative services and products, with a specific local appeal or generic consumer markets.

It can be used before and as a supplement for government support funds, business angels and bank loans, whilst enabling entrepreneurs to either grow their business organically or to scale the business fast through equity investment to make it attractive for early-stage venture capital funds.

Crowdfunders are motivated firstly by an emotional engagement and personal interest in a specific project that seeks funds. The emotional engagement is related to, amongst others, local needs, private preferences, or brand values that are attached to the project.

These are not emotional reactions on the macro level and thus have no systemic risk attached. This is in direct contrast to public markets, where uncertainty frequently creates fear and leads to significant but non-rational value destruction (or creation) as can be seen with the Euro Debt Crisis or with industry stocks and single stocks after public announcements.

Emotional engagement with a specific project aligns the crowdfunder with the entrepreneur. The funder ultimately takes a risk based on an intrinsic personal conviction of the project's possibilities, often mixed with additional expectations of social and financial return.

Crowdfunding combines the emotional engagement and dedication of entrepreneurship with the social and financial returns of investment, ultimately aligning the funder and investee in the early stages of business growth.

The users' direct influence and financial support become key factors in the successful delivery of the final offering with regard to value creation - the user becomes a co-creator.

In this way, crowdfunding changes the way we should see financial services and the involvement of consumers. Its mechanisms help to de-risk pre-seed to later-stage investments prior to committing funds, while provide input as to demand, pricing and validity of the business at the same time. 
According to the Harvard Law \& Policy Review, crowdfunding, in its various manifestations, promises to decentralise and generally transform corporate finance around the world. Where entrepreneurs and SMEs have difficulty accessing funding from traditional financial institutions, crowdfunding allows funders to utilise personal networks to fund their businesses and create jobs.

Studies from the Advanced Human Resource Studies Center at Cornell University show that remote work is often more productive than work in an office. The results of this are twofold: first, many companies are shifting towards a remote workforce, and second, workers are beginning to live outside of major urban centres.

This trend is inherently problematic for the entrepreneur seeking funding, as studies from Harvard Business School show that the entrepreneur's proximity to an urban hub (where venture capital companies are usually located) is connected to the decision of the venture capital company to provide funding. The research suggests that the farther away an entrepreneur lives from an urban hub, the less likely he/she is to secure venture capital funding.

However, for now especially projects with a regional or niche focus are able to attract support from the relevant communities, as they can develop a close connection to the project, and often meet face to face with the people behind the project. Fragmentation through language, tax and legal issues and regulation across Europe will contribute to this.

While we believe that this works well with relevant projects, we do not believe it adequate for more ambitions, scalable projects and their potential impact on society. Governments need to decentralise funding networks by providing crowdfunding investing frameworks, which allow funders to fund projects from anywhere on the globe. A crowdfunding framework both makes capital more available and more efficient, ultimately leading to higher GDP and more job creation.

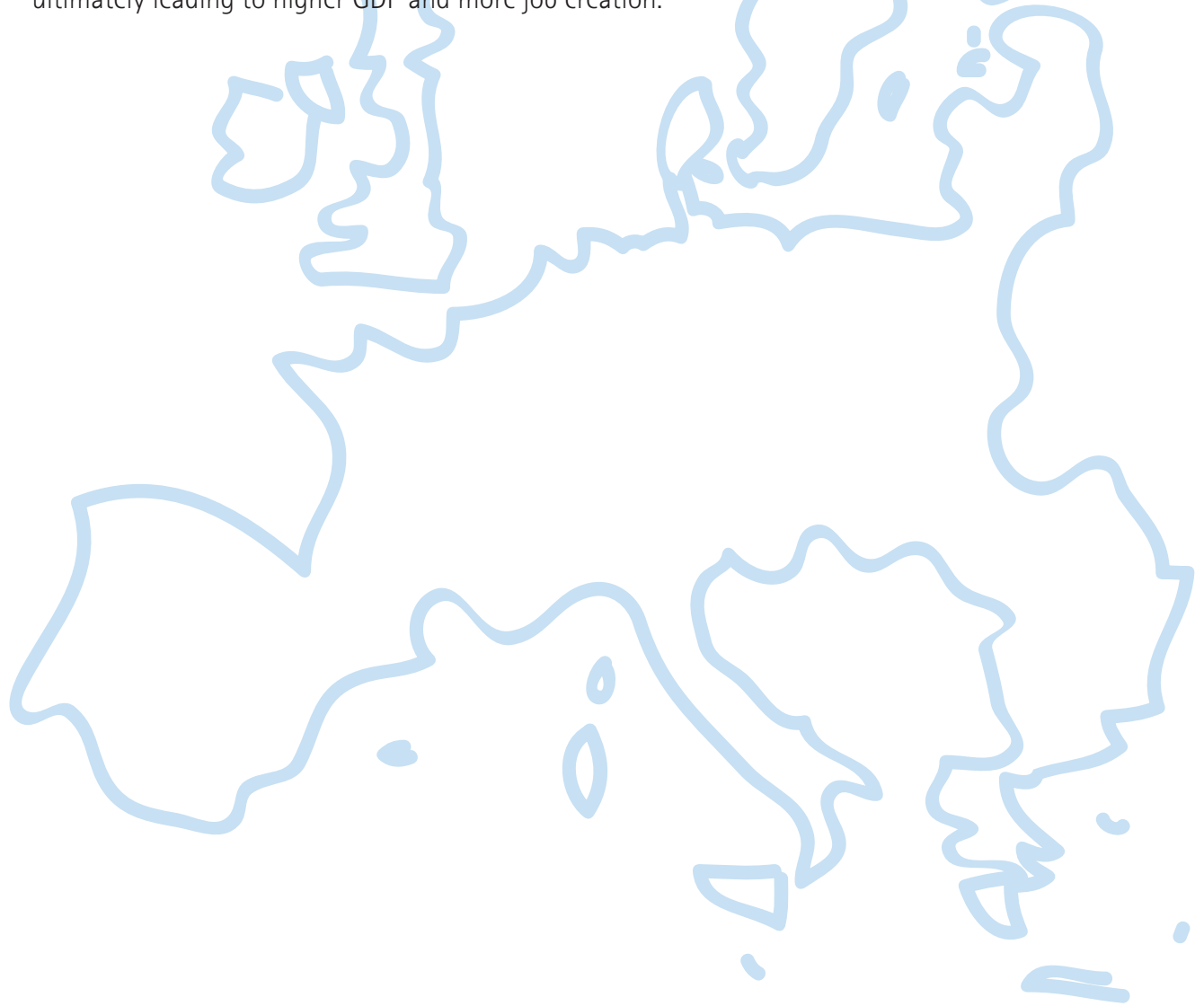




\section{THE EUROPEAN}

\section{Crowdfunding Market}

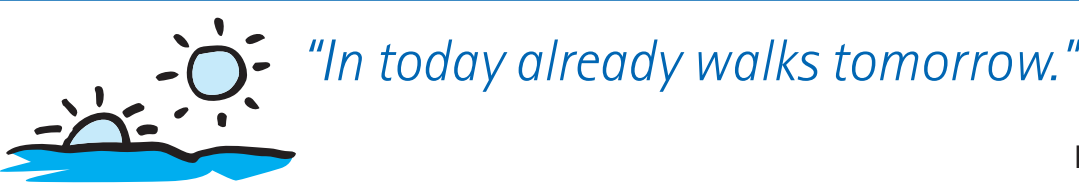

FRIEDRICH VON SCHILLER

At this juncture, there is no trade body surveying the industry. Private research firms have gathered market data and academics are conducting research and gathering data.

Unfortunately, comparative data is difficult to collect because of the regional nature and variation in crowdfunding business models. As a result, as with all non-public trades, the data presented here must be read with care and should be viewed as indicative rather than absolute.

We estimate $€ 2.2$ billion will be raised globally by crowdfunding platforms in 2012 , up $80 \%$ from $€ 1.2$ billion in 2011 and $€ 400$ million in 2009 (own estimates based on market interviews and research from Massolution 2012). The research states that worldwide there are over 450 crowdfunding platforms.

In line with this, the number of crowdfunding platforms active across Europe at the beginning of 2012 can be estimated at around 200, representing all types of platforms, slightly less than in North America. Their number is expected to rise another 50\% by the end of 2012.

With the US JOBS act and its potentially liberating effects on the crowdfunding market in the USA, one can expect a significant increase in crowdfunding platforms in the United States of America and a spill over effect to Europe. A number of large American crowdfunding platforms have already started their first ventures in Europe, hoping to establish a market presence against European platforms.

In 2011, considering all types of crowdfunding, Europe raised around more than $€ 300$ million, one third of the world market, through hundreds of thousands of crowdfunding campaigns. For 2012, the estimate is that $€ 2.2$ billion will be raised globally by crowdfunding platforms, up 80\% from $€ 1.2$ billion in 2011 and $€ 400$ million in 2009 .

Again, this number reflects efforts by the various types of crowdfunding platforms. We believe it is important to stress that we do not raise one business model above the other, but that we think all of them have an equal place in the modern economy.

In Europe, the split between the different crowdfunding types shows nearly half of all activity from reward based approaches, with fewer than one quarter for platforms from donation based approaches, as well as equity based approaches. Lending or debt based approaches make up for the remainder.

In comparison, in the USA donation based approaches dominate while equity based approaches reach only a symbolic percentage due to legal constraints.

The number of crowdfunding campaigns is driven by donation based approaches, as the funding targets involved are generally much smaller than, for example, equity based funding targets. 
However, an increase in campaigns can be seen for all four different approaches, with campaigns in reward based approaches increasing more than five times over, compared to a doubling in number of equity based campaigns and increases of around 50\% for donation and three quarters for lending and debt based campaigns.

We estimate European averages per campaign are around $€ 500$ for donations, $€ 3,000$ for reward, $€ 4,500$ for lending and debt and $€ 50,000$ for equity based campaigns, though for the latter there are already a significant number that reach the maximum of $€ 100,000$ through the use of co-investments from professional investors. We estimate that averages will double or triple within a short period of time, especially for lending.

Naturally, an enabling regulatory framework could smooth the development significantly and help economic growth through resulting innovation and entrepreneurial activities.

There are significant differences in the various crowdfunding models described earlier and the market data confirms these. While donation and reward based approaches are targeting smaller campaigns, they are also focused more on societal, health and environmental issues as well as on education, community and religion.

Reward based approaches are also used frequently for product finance of creative projects, especially within film and music, but also for technology products. Lending and debt based approaches are usually peer-topeer platforms, where individuals can lend each other money for specific purposes at better lending rates than banks offer.

Equity based approaches are still rare. They focus on equity in start-up companies or small and medium sized companies, where equity stakes in the tens of thousands of Euros makes economic sense. This is especially true for software and internet businesses, but also in computer and telecommunications related areas, in consumer products, media and the environment. In the USA, equity crowdfunding is only anticipated to be possible with the implementation of the JOBS Act.

The average crowdfunding campaign takes just under three weeks to raise the first quarter of the funds sought, though lending based campaigns hit their goals faster, in about half the time of equity campaigns. In general, crowdfunding campaigns run anywhere from five to ten weeks, with lending campaigns completing within five weeks, equity in around eight weeks, and lending and donations in around ten weeks.

According to research (Massolution 2012), the average funders of crowdfunding platforms are involved in one or two projects, and 10\% of funders have participated in multiple projects. Nearly $70 \%$ of fundraisers of crowdfunding have started one or two campaigns, and only a little more than $30 \%$ have started more than two

This data indicates that while crowdfunding is already attracting many people, it has not yet reached maturity to rival incumbent financial services. There is a healthy respect for the risks among the early adopters and existing users, which allows crowdfunding platforms to carefully improve their client protection and education efforts. 


\section{BENEFITS FOR THE INTERNAL MARKET}

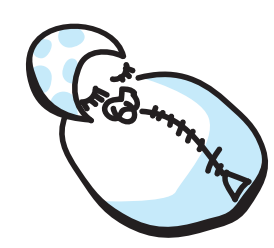

"There is the greatest practical benefit in making a few failures early in life."

THOMAS HUXLEY

\section{SYSTEM RESILIENCE}

We hope the crowdfunding industry evolves into a structure where market share is significantly less concentrated than in incumbent financial services. Numbers show that the banking industry is run by a select few organisations who widely dominate the entire market. This situation can create the 'too big to fail' financing model, where the largest institutions bear the risk of making the whole system collapse on default.

Regulators and the public should stand for building a crowdfunding industry where no single player can possess overall market share, both in volume and in numbers of projects funded. With more than 200 platforms present in Europe today, there should be ample room to achieve a higher level of diversification and resilience of this industry.

Systemic risks recently encountered by the financial system would be lowered by the intrinsic nature of the crowdfunding industry to operate as highly inter-connected networks.

\section{BETTER MARKET RATES DISCOVERY}

Because rates are defined by the demand of the crowd, leading crowdfunding platforms will enable true return and price discovery for many financial aggregates that are nowadays controlled by a handful of financial institutions.

It is known that the basis of interest rates used within the global financial industry can be manipulated by very few individuals or organisations. They therefore bear the risk of not being relevant for the economy.

Crowdfunding possesses the ability to generate real market prices and real interest rates, in the sense that they would be per definition highly accepted and thus generating opportunities for continuous high liquidity.

\section{FUNDING DIVERSIFICATION}

SMEs find it hard to both secure long-term financing and find sources of revenue outside investment banking.

While crowdfunding offers new investment opportunities to individuals and corporate investors, it also offers recipients of funding the ability to diversify their sources of funding. This lowers their funding risk and creates value for the system as a whole, again making the business less prone to funding shortages, therefore allowing them to better able to pool resources on significant business opportunities.

This feature has the potential to make entire industries competitive on a global scale. 


\section{FINANCIAL STABILITY}

Historically, a crisis has often been caused by a sudden drop in funding flows (velocity), a subsequent public spending re-balancing, and by unsustainable deficits experiencing contraction.

While crowdfunding does not annihilate the risk of significant drops in funding flows, it still generates new financial ties and opportunities for existing funds to be re-invested in tangible projects that bear a return to investors. Therefore, money is less likely to stop flowing when investment opportunities still exist and are readily available.

This represents a significant alternative to money creation for economic crisis management and also reduces the risk of over inflation caused by artificial inflows of investment into the economy.

\section{Alternative finAnCing CHANNELS}

The inherent ability to generate data and accurately describe projects enables governments to better target key areas of investment. In the short term, governments and public bodies will find opportunities to leverage a highly interconnected network of funding channels that will create better visibility of actual funding needs within the economy.

Where public funds are now 'pushed' to certain areas and investment segments with a long investment cycle, with crowdfunding these can now be operating with 'pull' dynamics, where certain public funding envelopes are used only if the actual demand for funds is actually there. In the long term, it could also decide to favour certain investment channels and industries (e.g. with tax incentives). All these can be operated through crowdfunding platforms.

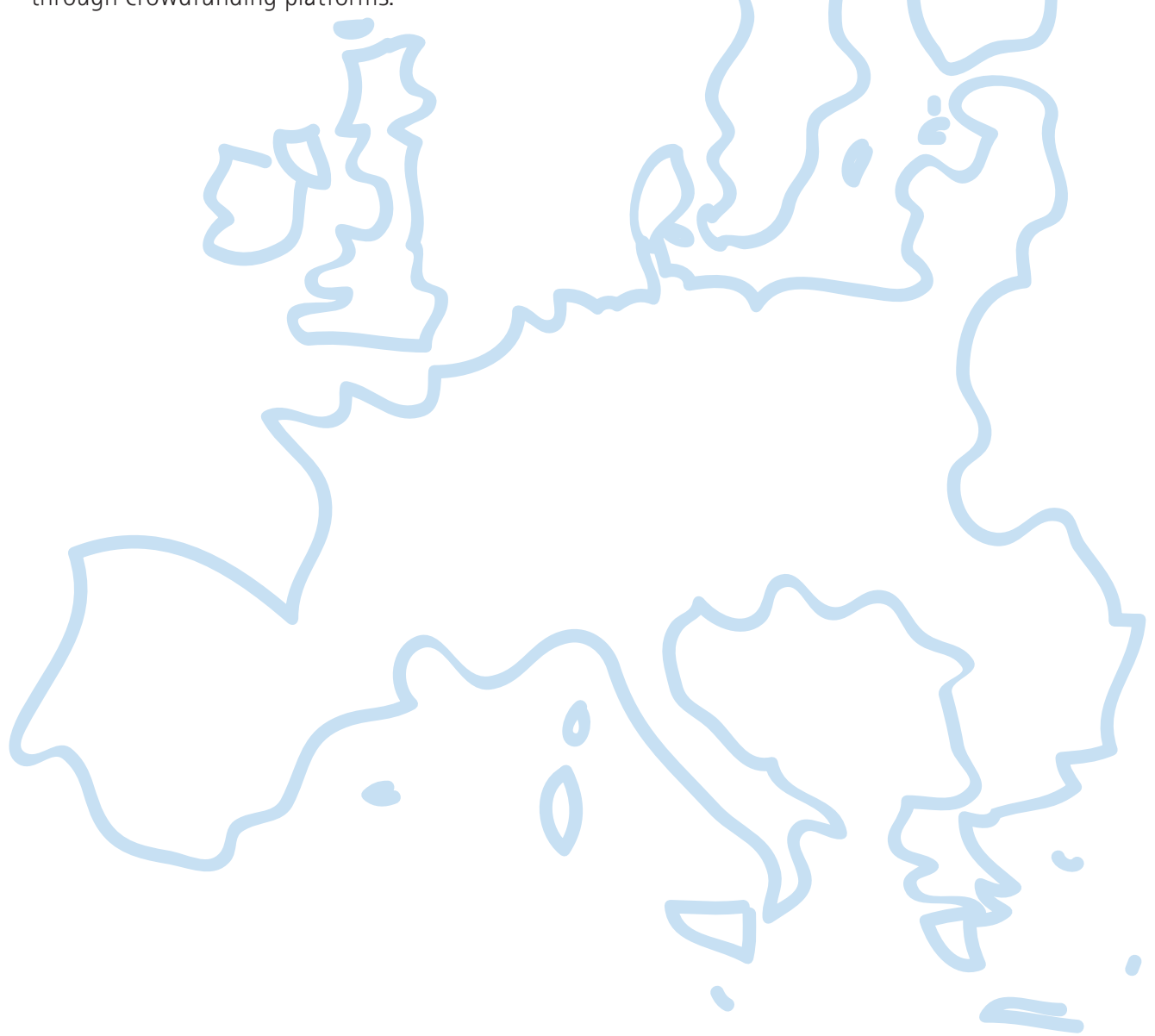




\section{Policy Discussion in EUROPE}

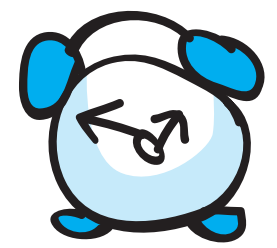

\section{"A policy is a temporary creed liable to be changed, but while it holds good it has to be pursued with apostolic zeal."}

MAHATMA GANDHI

Many of Europe's challenges come from the fact that its overall legal and regulatory framework leaves too much opportunity for fragmentation through varying national interpretations. The same goes for access to finance for Small and Medium Sized Enterprises (SMEs).

In 2011 the European Commission issued an action plan to improve access to finance for SMEs. It outlines the key obstacles with regard to access to finance SMEs in areas such as loans, venture capital and capital markets. The plan describes measures taken since 2007 to foster access to finance for SMEs, including the Competitiveness and Innovation Programme (CIP), the European Investment Bank allocation for SME loans, cohesion policy funds and the Risk Sharing instrument in the European Commission's Framework Programme 7.

In order to build on these the European Commission identified further measures aimed at improving access to financing for SMEs, such as regulatory measures, financial measures to improve lending and venture capital across the European Union and measures to improve the environment for SMEs.

The action plan did thus discuss a number of highly important issues in order to improve entrepreneurship in Europe, it however did not include crowdfunding as an highly innovative option for seed and early-stage equity funding, debt and lending instruments or a highly efficient tool to pre-validate business ideas and products in the market.

Also in 2011, the participants of the Agorada 2011 + Conference, an international summit in Bielsko-Biala, co-authored a paper now known as the Bielsko Biala Declaration - Maximising the Opportunities offered by Crowdfunding. The declaration consists of six small paragraphs addressing the EU administration, Member States, and Regional Authorities.

The declaration argues that the underlying aim of crowdfunding is to provide entrepreneurial and innovative projects the financial means to execute. Public authorities should have an interest in supporting the development of crowdfunding in order to remove barriers to entrepreneurship and to facilitate a favourable legal framework, while maintaining the minimum of professionalism and regulation.

The declaration continues that crowdfunding needs to be better understood, and to this end, relevant data collection should be encouraged and data should be benchmarked. To help smooth the fragmented European market, crowdfunding should be welcomed and promoted at a European, national, and regional level.

These six high level statements point in the right direction, but in the authors' opinion, leave room for improvement. We believe that the crowdfunding industry has a vital role to play in defining best practices for operations, customer protection, data collection, stakeholder education, and regulation. 
We also believe that European, national and regional regulators and legislators may be interested in receiving input about crowdfunding from the industry so they can produce ample guidelines in turn. We therefore welcome the initiative of Start-up Exemption in the United States of America. After more than a year, the USA was rewarded for their efforts in drawing up a regulatory exemption framework that positively enables crowdfunding to become a driver for job creation and economic growth.

The framework has, in adapted versions, passed the US House of Representatives as the Entrepreneur Access to Capital Act with 407 votes against 17 on 3rd November 2011. It is also the foundation for Democratization of Capital Act submitted in the Senate. It has been referenced by President Obama in the American JOBS Act.

The exemption framework consists of just a few bullet points, but unlike the European call for support, it lists actual exemptions to be implemented by the legislators. It addresses definitions of share structures and amounts for small business funding, investment limits for unsophisticated or unaccredited investors, risk disclosure, number of investors, and filing and reporting requirements.

While the exemption framework for crowdfunding developed in the USA is far more practical than the Bielsko Biala Declaration, the USA framework is impractical for the fragmented European market. However, if crowdfunding is to succeed in bringing about economic growth, job creation, and financial stability, it is critical that the European discourse is held on both levels.

While we are mindful that official legislation and regulation may not happen overnight, it is crucial that we move forward with urgency. The passing of the JOBS Act in the United States has accelerated the growth and significance of crowdfunding in the American economy.

A competitive edge for America will create adverse circumstances for the European crowdfunding industry, investors and entrepreneurs, but may also hinder economic growth and job creation. Crowdfunding legislation and policy will ensure balanced global economic power distribution.

We are aware that crowdfunding is being discussed seriously within the European institutions as an alternative for SME financing, especially with view on the Europe 2020 strategy. We also believe that proposed regulation that will introduce new pan-European banking regulation will present an opportunity for crowdfunding.

Earlier in 2012, an expert group for the Directorate-General for Enterprise and Industry at the European Commission working on cross border matching of innovative firms with suitable investors, called for the European Commission to monitor the emergence of new sources of funding that employ social media.

The working group argued that the "fragmented European regulatory environment along national lines for cross border platforms are among the emerging challenges which pose issues for entrepreneurs, platform providers and investors alike."

The expert group stated that crowdfunding may indeed have the potential to become an important source of SME funding at the seed stage for equity capital. In conclusion, the expert group called to encourage crowdfunding in Europe without over- regulation, but with adequate investor and entrepreneur protection.

A recommendation went to the European Commission to set up a specialist expert group to review the subject of crowdfunding, drawing on existing experiences in Member States and elsewhere internationally. The European crowdfunding industry and the European Crowdfunding Network would be well suited to join such dialogue. 
In September 2012, the opinion of the European Economic and Social Committee (EESC) on the communication from the Commission to the Council, to the European Parliament, to the Committee of the Regions, and to the European Economic and Social Committee, created an action plan to improve access to financing for SMEs.

The opinion, issued in 2011, was made public. A public hearing at the EESC was held June 2012 at which representatives of the crowdfunding industry were present. The crowdfunding industry was invited to provide a public intervention via the European Crowdfunding Network. The thorough review of SME financing options concludes that "Europe's economic recovery can only be achieved if SME policy is high on the agenda of European policy-makers."

The EESC supports the efforts of the European Commission and other institutions to increase the resilience of the financial system in order to create an instrument at the disposal of the real economy.

The opinion also concludes that crowdfunding is a good example to mention and participative banking could be another option to take into consideration alongside all other proposed actions to improve access to finance for SMEs. In addition, the EESC opinion stresses that crowdfunding can be supportive to equity investment and urges the European Commission to look at innovative approaches to venture funding.

Together, the European crowdfunding industry and the European legislators and regulators must collaboratively enable economic growth and job creation from the bottom up. Should Europe decide to encourage the crowdfunding industry and find itself in a position to compete with non-European future global players (especially those with significant access to growth capital from the Americas and Asia), we will need to establish a European framework and ecosystem for best practices.

Innovation comes from changing the way we think about and work with financial services. We ask the European crowdfunding industry to work on open self-regulation and transparency, customer protection and data collection, and the European legislators and regulators to proactively develop an understanding of crowdfunding and to support the crowdfunding industry by providing relevant exemptions and guidance.

By working together to ensure crowdfunding as a sustainable and safe financial service offering to entrepreneurs and funders alike, we will be in a position to mobilise billions of Euros for the purpose of investment in customer-approved innovation and entrepreneurship.

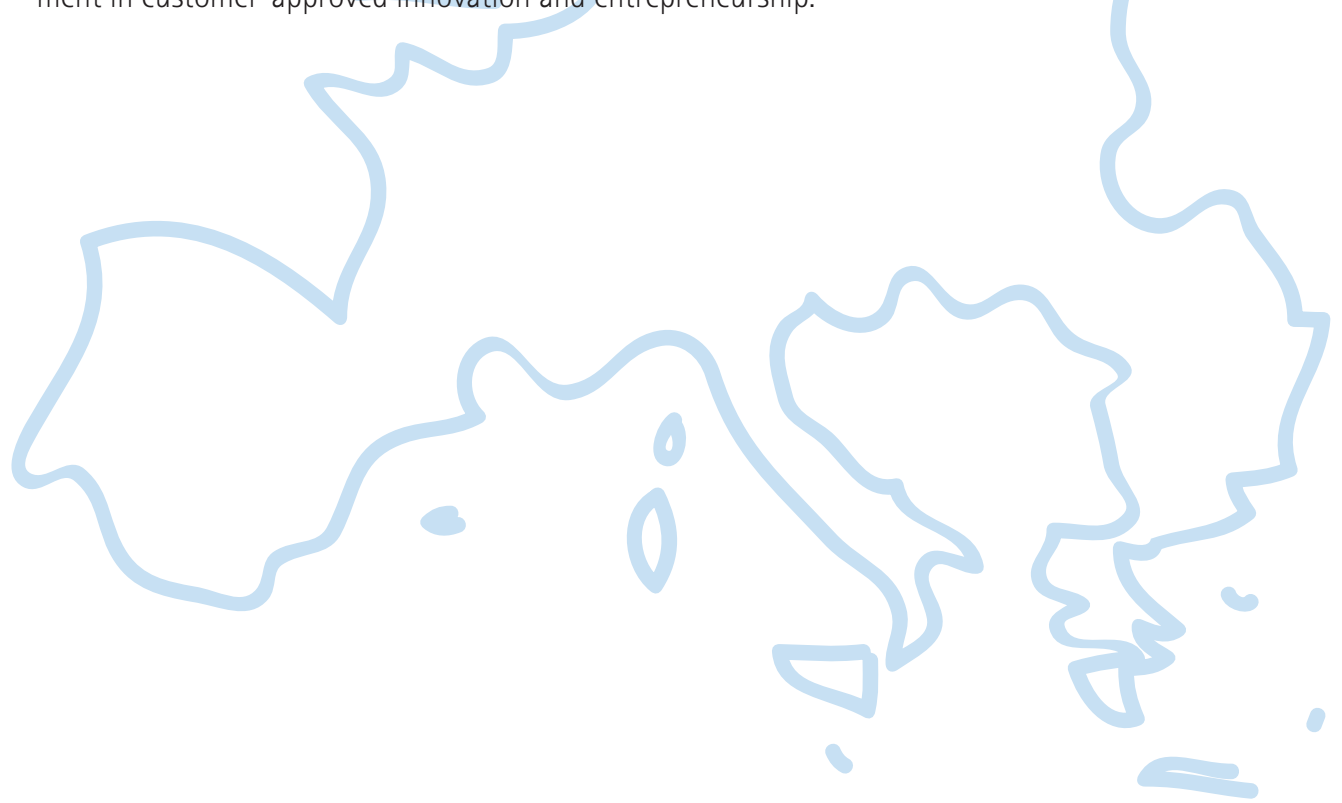




\section{EUROPEAN REgulation AND}

\section{LEGISLATION}

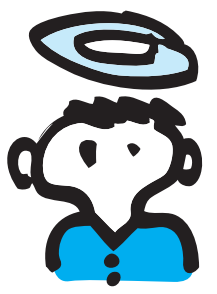

"Virtue is more to be feared than vice, because its excesses are not subject to the regulation of conscience."

ADAM SMITH

Financial regulation and legislation has the duty to stimulate efficient and transparent markets while ensuring investor protection. This should also include the possibility of creating crowdfunding venues or platforms. Currently, efficient and transparent markets cannot arise in the field of equity and loan based crowdfunding because investor protection regimes are designed for incumbent investment settings which exclude a large number of crowd funders.

This heavily restricts investment choices for European citizens and funders that want to express their support for economic or social initiatives. Legislation should not obstruct access to assets where users want to fund value creation - for both, financial and non-financial reasons.

\section{REgulations IMPACTING THE PROMOtion OF CAMPAIGNS (2003/71/EC)} Based on current experience, crowdfunding will generally remain below the $5 \mathrm{~m}$ threshold, where the Prospectus Directive (2003/71/EC, amended by 2010/73/EC) offers freedom to national lawmakers to implement a country-specific promotion regime. This freedom has resulted in many different national regimes ranging from full prospectus regimes to complete exemptions.

Although the Prospectus Directive also contains a harmonised exemption that even pre-empts national regimes, namely for campaigns that do not exceed $€ 100,000$, this does not create a Europe-wide level playing field because many campaigns may exceed the $€ 100,000$ threshold.

The Prospectus Directive can be improved to include harmonised pan-European rules or exemptions in the sub-€5 million region to reduce the compliance cost for pan-European crowdfunding initiatives, and to prevent the situation where disproportionate compliance costs would deprive start-ups in some countries from cross-border fundraisings above $€ 100,000$.

Although current exemptions in the Prospectus Directive theoretically only apply to the obligation to publish a prospectus, it would be advisable to extend this to the preparation and approval procedure for such prospectus or prospectus-grade document. This is a guarantee against additional potential national regulatory layers of fundraising promotions rules.

Finally, an additional exemption which is based on an investment cap per investor or per campaign might be suitable for crowdfunding in order to provide protection for investors.

We ask the European Commission to create a pan-European harmonised regime for sub- $€ 5$ million offerings - instead of excluding sub- $€ 5$ million offerings from the full harmonization regime of the Prospectus Directive (see article 1, 2 (h) of the Prospectus Directive). Such a harmonised regime may, for instance, take the form of a full exemption below a certain threshold and a light regulatory regime above that threshold but below $€ 5$ million. In the event of a light regulatory regime, above a certain threshold, it could also include a European Passport for the promotion. 
In case the European lawmaker would fail to come up with a maximum harmonization in this sub- $€ 5 \mathrm{~m}$ domain, then we ask national governments and regulators to coordinate their national freedom, in order to move away from country-specific sub- $€ 5$ million regimes and to coordinate a common regime in favour of crowdfunding.

\section{CORPORATE LAW PROVISIONS IMPACTING THE ABILITY TO OFFER DIRECT EQUITY TO CROWD INVESTORS}

Start-ups typically choose relatively inexpensive corporate entity types. In most countries, this means that they choose for a closely held company type. However, by choosing such closely held (or often "simplified") company type, they unintentionally run into limitations to offer equity to new and yet unknown investors. This may vary from formalities (notarial intervention) to outright prohibitions to accept such new shareholders.

This is obviously an undesirable feature in the inexpensive corporate entity types. Also, it should clearly be asked if the formalities that are in many cases involved with equity transaction, are still suitable in the information age. Today, even share trading in public companies is entirely organized in a dematerialized way, by means of bookkeeping entries.

We recommend to harmonize or coordinate company laws, and to offer features from public company types (which are not necessarily listed companies!) to the "cheaper" company types

\section{REGULATIONS IMPACTING ARRANGING AND DEALING (FOR Platforms)}

There is room for interpretation of European regulation on member state level. As a result, there are different views in different countries regarding "acceptable" transaction structures. A regulator in one country may find one transaction structure more acceptable, and another regulator may potentially find that the same structure (or even all structures) unacceptable and may potentially find yet another transaction structure acceptable.

For example, crowdfunding structures usually focus on arranging transactions between investors and investees directly, be it loan, equity or otherwise, but in case of equity crowdfunding many platforms act as a central counterparty between the investor and the investee in order to accommodate limitations or costly formal steps in company laws to accept new and unknown shareholders. Ultimately, the investor will then receive equity in an intermediate entity, or he will be a creditor of that intermediate entity through an equity-like contract.

We ask the European Commission for intervention to avoid a highly investor-unfriendly situation whereby every platform operates a different transaction model, depending on the country where it is based (thus depending on the type of model that the regulator in that country deems acceptable). Such intervention should however be immune from simply favouring or preferring crowdfunding transaction models from existing platforms. Indeed, some crowdfunding platforms already started operations despite the regulatory burdens, but this may certainly not result in rent-seeking behaviour, by seeking approval for "their" transaction model. 


\section{ACCEPTING RECLAIMABLE FUNDS}

\section{(DIRECTIVES 2006/48/EC \& 2009/110/EC)}

Under European regulation, accepting reclaimable funds from the public requires a license as a credit institution. Electronically storing a monetary value to be used for payment transaction (i.e. before a loan is arranged between the investor and investee) also requires a license as a credit institution.

Such license requirements may aim to help separate investor funds from the platforms' own funds. Platforms (which are typically unable to meet the license requirements to become a credit institution) may comply with such requirements by entering into an arrangement with a licensed service provider that will act as the acceptor of the reclaimable funds.

By offering investors the chance to reclaim funds if a campaign fails or if funds have not been allocated to campaigns, platforms offer customer protection. The crowdfunding platforms do not use the funds to pursue money creating activities. Yet by doing this, they face the highest regulatory burden and the highest cost, either by having to obtain an expensive license as credit institution, or by having to cooperate with a licensed third party, as possible under the e-Money Directives, to accept the money from investors.

We ask the European Commission to offer an exemption or light license to e-commerce operators (in this case crowdfunding platforms) that accept reclaimable funds or funds that will be used to electronically store and represent money in accounts (thereby potentially falling under directives 2006/48/EC \& 2009/110/EC), as long as mechanisms are used whereby funds are separated from the platforms' funds in case of bankruptcy and as long as no money creation takes place.

\section{COLLECTIVE INVESTMENT UNDERTAKINGS}

Some platforms that act as a central counterparty between investor and investee, and at the same time opt to deal in equities, fall outside the harmonised scope of the Undertakings for the Collective Investment in Transferable Securities (UCITS) directives, and the Alternative Investment Fund Managers (AIFM) directives. Otherwise, such regimes would be prohibitively costly.

Instead, they are subject to country-specific regimes (both in terms of operations as in terms of marketing of the stakes), which hinders the possibility to operate a pan-European transaction model based on intermediate counterparties between investors and investees.

This hinders the emergence of a market with strong network effects. This lack of EU-wide level playing field for non-UCITS and non-AIFM collective investment undertakings has already been highlighted in other contexts, for instance by the investment fund industry as a reaction to the Commission Green Paper on Asset Management from 2005.

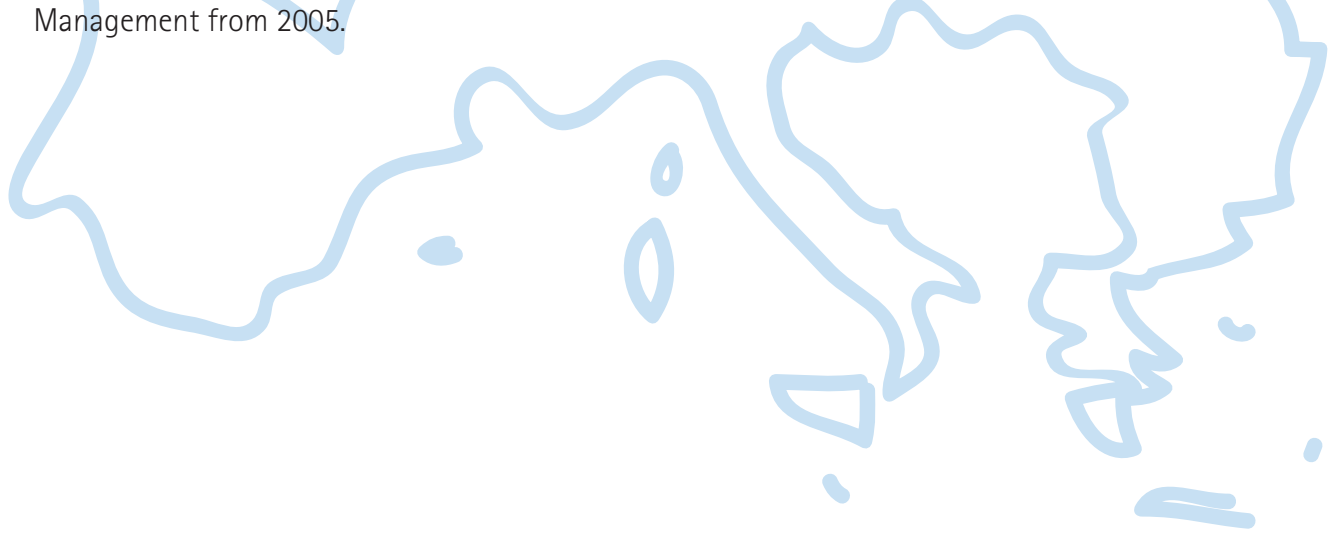


In case specific considerations would be made for crowdfunding platforms, then it should be noted that many platforms under this transaction structure do not manage the stakes on a discretionary basis.

We ask the European Commission to harmonise collective investment activities that are currently not harmonised under Undertakings for Collective Investment in Transferable Securities (UCITS) or Alternative Investment Fund Managers (AIFM) directives, and that may be suitable for crowdfunding platforms that pool amounts of money that do not represent the same type of systematic risks that are normally associated by the much more substantial amounts in case of UCITS or AIFM activities.

In case the European lawmaker would fail to come up with a maximum harmonization, then national governments and regulators should coordinate collective investment undertaking regimes that are currently below the harmonization thresholds of the AIFM directive, or outside the scope of UCITS directives.

\section{MIFID - IMPACTING THE CONDUCT OF BUSINESS OF PLATFORM OPERATORS}

Some activities regulated by the Markets in Financial Instruments Directive (MiFID) may face different national interpretations as to whether a platform transaction structure classifies as such an activity or not. This is especially true for the placing of financial instruments, execution of orders on behalf of clients, reception and transmission of orders in relation to one or more financial instruments, operating a multilateral trading facility, operating an organised trading facility (under MiFID II) and services related to underwriting.

Platforms can find very strong arguments against such qualifications, depending on their transaction model, including

$\rightarrow$ That loans or equities will not always qualify as financial instruments (thus no reception and transmissi on of orders, and not placing of financial instruments),

$\rightarrow$ That the platform will not act as an agent for the campaigner (thus no placing of financial instruments) or

$\rightarrow$ That there will be no multilateral mechanism where multiple participants compete for the best price (thus no multilateral trading facility).

Nonetheless, there is a substantial risk to be qualified as such a regulated activity by any given national regulator. The MiFID directive does not foresee the issuance of a legally binding opinion from a regulator or a no-action letter, which creates substantial operational uncertainty for crowdfunding platforms, especially those operating in multiple member states.

It is likely that the proposed regulated activity of "operating an organised trading facility" will also apply to crowdfunding platform operators. It may not be illogical to qualify under some sort of regulation, but the regime should be proportional and manageable from an organizational point of view. This may require an exemption. 
Platforms can adapt the MiFID regime now under prohibitively high cost, perhaps in order to enjoy the legal certainty to operate cross border under the European passport for one (or more) of the relevant activities. This may create a user unfriendly situation where clients have to be categorised according to MiFID requirements. In addition, treating both investees and investors as clients may create problems under the inducement rule, which forces regulated firms to operate in the best interest of their clients (which conflicts in this case).

We ask the European Commission to clearly define activities that are mentioned in the annex of the Markets in Financial Instruments Directive (MiFID) directive, to avoid any different interpretations and legal uncertainty as to whether a specific crowdfunding platform setup falls within the scope of such an activity or not. Also, if this would eventually lead to a classification as a regulated activity, then some exemptions might be suitable. For instance, to prevent that qualification as Organised Trading Facilities (in upcoming MiFID amendments) would result in organisational burdens for startups operating crowdfunding platforms.

\section{Crowdfunding DiReCtive}

While a Crowdfunding Directive does not yet exist, we may be forgiven to envision one similar to the Payment Services Directive and Electronic Money Directive, defining a role of a "Crowdfunding Provider" maybe similar in concept to the US Funding Portal, but detached from a specific financial instrument. Here the notion of single European passport for this role could create legal certainty to be able to operate on a cross-border basis without facing new compliance costs and procedures.

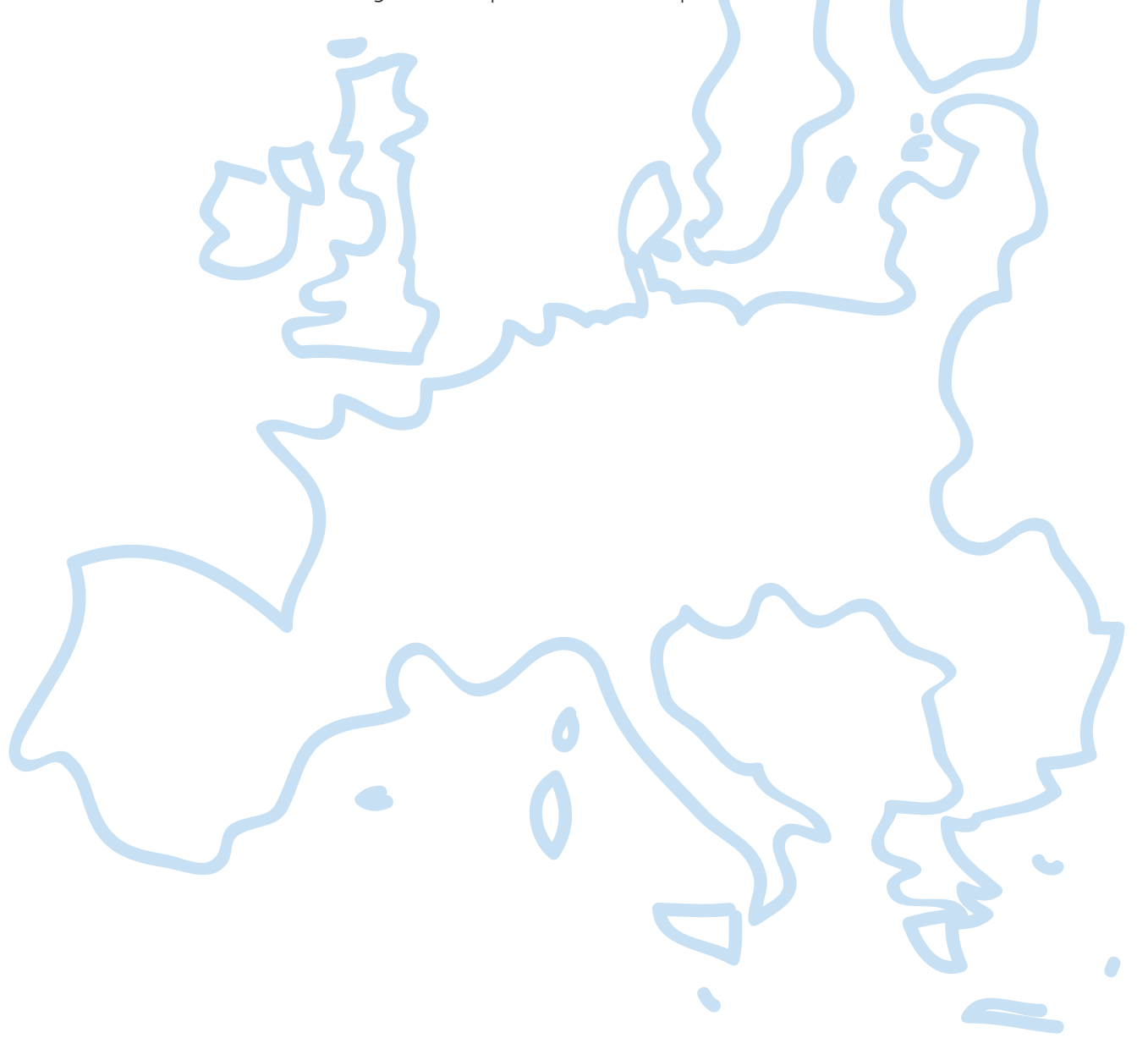




\section{The Pillars of a Crowdfunding}

FRAMEWORK

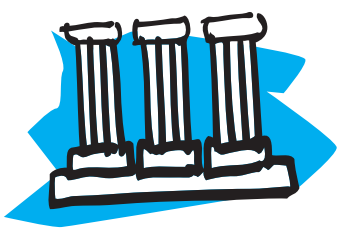

"Seeing much, suffering much and studying

much, are the three pillars of learning."

Benjamin Disraeli

If we are to realise the true potential of crowdfunding in Europe, the industry must create a collaborative and open discourse amongst the industry, regulators, and citizens can generate the necessary consent on best practices, reflecting the needs and specifics of different crowdfunding business models.

We believe a European Crowdfunding Framework should include the following pillars: Regulation, Education, and Research.

\section{REgULATION}

Regulation is critical. However, we are not advocating regulation for regulation's sake.

Instead of imposing heavy regulations that are likely to become more confusing between nation-states, we should look at crowdfunding intermediaries passing qualification criteria focusing on the following categories: operational and financial transparency, security of information and payments, platform functionality, customer protection, and operational procedures.

There might also be room for open collaborative self-regulation and accreditation, ultimately signalling a level of credibility to funders, entrepreneurs, and other stakeholders.

\section{EDUCATION}

Education and training are central in the implementation of crowdfunding into the European economy. Providing entrepreneurs with access to information on how to run a successful campaign, identifying which type of crowdfunding is best for their business, and educating funders on how to choose a campaign are a few steps we believe will ensure best behaviour and best practices within the industry.

According to a study by Cutting Edge Information, online training may be one of the most effective and efficient means to provide regulatory compliance, as well as educate potential funders. Examples of educational efforts include the Australian government and the Australia Council for the Arts which embarked on a national strategy to explore the opportunities in crowdfunding for cultural and creative projects.

Their "National Crowdfunding Roadshow" offers citizens practical tips on running a successful crowdfunding campaign, testimonies from entrepreneurs with successful campaigns, and the results of research commissioned by Queensland University of Technology Creative Industries. 
www.crowdfundingframework.eu

\section{RESEARCH}

There is great potential for academic and third-party analysts to work with data from the crowdfunding industry. There is a dearth of start-up information to analyse, and we are beginning to witness universities publishing academic papers on crowdfunding. The findings will be of central importance in helping entrepreneurs create the top tier crowdfunding platforms and run successful campaigns.

Without doubt, positive findings of transparent research will also help shape a positive public image and support amongst policy makers. For this to happen, we would look to crowdfunding platforms to provide transparent and open data sets to researchers and industry representations.

\section{The Pillars of the Crowdtunding Framework}

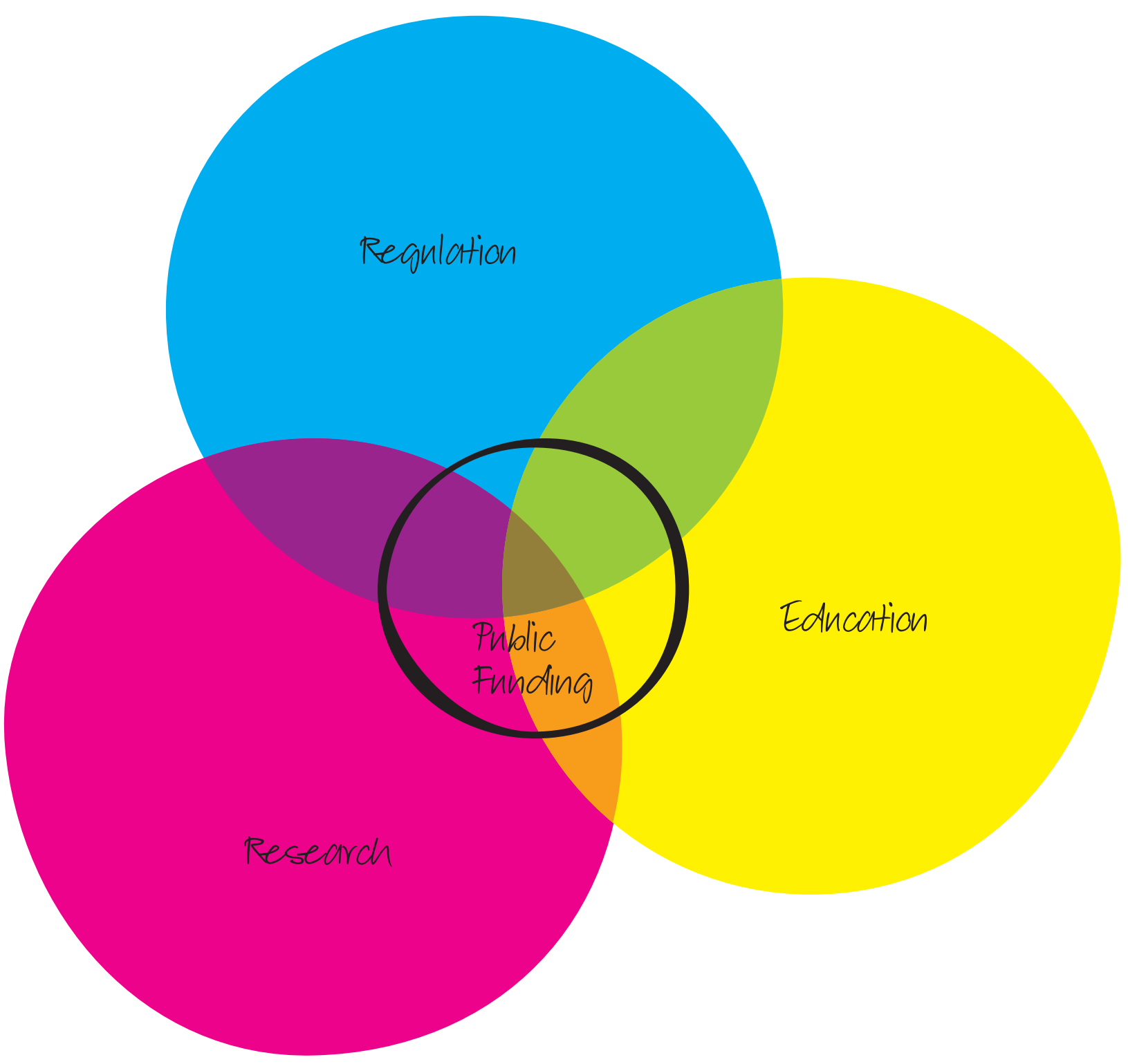




\section{IMPLEMENTING AN OPERATIONAL FRAMEWORK FOR EUROPEAN CROWDFUNDING}

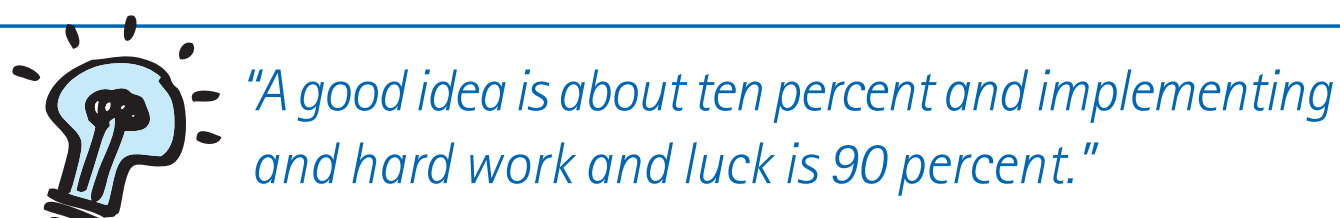

GUY KAWASAKI

\section{Call to European, National, and Regional Regulators AND Policy Makers as Well as StaKeholders:}

Europe's economy needs bold actions. The opportunities offered by entrepreneurship require a new mentality for the provision of funding and risk sharing.

When the traditional financial markets began to fail, small businesses were starved for capital bearing in mind, small and medium sized businesses in Europe are responsible for the majority of job creation. Crowdfunding can play an important role in this.

To help build a sustainable and competitive crowdfunding industry, national and European policy makers might consider initiating public funding structures that can co-invest alongside crowdfunding campaigns in order to leverage private investment, as exist for venture capital, and consider allocating funds to support a diversified European crowdfunding industry during its early days.

Therefore European, National and Regional Regulators, and Policymakers should:

\section{REgULATION}

$\rightarrow$ Update the laws to allow small and medium businesses the opportunity to raise capital through their own personal networks to ensure their autonomy and job-creating capabilities.

$\rightarrow$ Oversee the creation of Expert Groups on Crowdfunding, tasked with the collection and exchange of ideas on how best to support crowdfunding on European, national and regional level.

$\rightarrow$ The European Commission should consider the input from the European Economic and Social Commit tee, its own Expert Group on the cross border matching of innovative firms with suitable investors. It may consider an Expert Group on Crowdfunding joining multiple Directorates Generals, building on the success around their work on Social Businesses.

$\rightarrow$ Create a business case for crowdfunding in Europe, build awareness for SMEs on how to utilise crowdfunding and create guidance for best practices for crowdfunding platforms, entrepreneurs, and funders

$\rightarrow$ Coordinate and relax the rules in company laws under which entry-level company regimes can offer and assign shares to new investors, thereby abolishing formal procedures that do not fit the information age. 


\section{EDUCATION}

$\rightarrow$ Provide any type of support to platform managers in view of helping them sustain their activities just like they provide support to any intermediary organizations offering services to entrepreneurs and enterprises.

$\rightarrow$ Signpost crowdfunding platforms to innovators, entrepreneurs, artists and any project promoters.

$\rightarrow$ Raise awareness of potential investors, donors, lenders about the opportunities offered by crowdfunding platforms.

$\rightarrow$ Utilise a range of different strategies and approaches to encourage SMEs and entrepreneurs to utilise crowdfunding.

\section{RESEARCH}

$\rightarrow$ Fund academic and market studies addressing the impact of crowdfunding on the economy.

$\rightarrow$ Initiate and fund studies on pan-European, national, regional, and local communities; ways SMEs can utilise crowdfunding; the success or otherwise of different policies and techniques that can increase the use of crowdfunding in Europe.

$\rightarrow$ Provide resources and funding to a representative body of the European crowdfunding industry (such as the European Crowdfunding Network or a similar organization).

\section{CALL To INDUSTRY LeAders:}

The European crowdfunding industry needs to proactively help the European entrepreneurs, funders, legislators, regulators and other stakeholders to understand, support and use crowdfunding. We believe that a professional industry body should represent the crowdfunding industry across Europe, such as the European Crowdfunding Network. Such a body could also manage accreditations where necessary. There might also be possibilities to work with existing trade bodies that have similar interests.

We also believe that national collaboration is urgently needed within European member states. National efforts should aim at fostering favourable conditions for crowdfunding within their legislation, but with a view to a harmonised European framework for crowdfunding.

It is important to define what acceptable behaviour from a crowdfunding platform is and what is not. There needs to be enough flexibility and room for change to allow adaption of innovation in the sector. At the same time, fraudulent behaviour and actions leading to unprotected insolvency must be prevented in order to ensure a sustainable future of crowdfunding for the benefit of the European economy.

The industry should:

\section{Regulation}

$\rightarrow$ Openly adopt a transparent code of conduct and communicate this to the public and stakeholders. We believe that establishing a code of conduct early on will have a positive and stabilising input on the future of the industry.

$\rightarrow$ Establish transparent reporting guidelines and documents, such as generic time-sheets and subscription agreements. Moreover, entrepreneurs should be asked to provide automated reporting to their funders on a timely basis.

$\rightarrow$ Address customer protection and generate reasonable and fair guidelines relating to the financial inte rest, exposure and diversification of funders and investees across multiple crowdfunding business models. This needs to provide guidance around fraud, risk explanations and potentially the testing of funders' knowledge.

$\rightarrow$ Customer identification is a key issue with both projects and funders; this includes know-your-customer, customer due diligence procedures and anti-money laundering aspects. The industry needs to create a relevant dialog and approval processes for best practices for customer due diligence. 


\section{EDUCATION}

$\rightarrow$ Invest in training and awareness raising for entrepreneurs and funders.

$\rightarrow$ Promote its success and abilities in growing local, regional and pan-European economies and job creati on by financing entrepreneurial and innovative projects.

$\rightarrow$ Educate the public as to the benefits of crowdfunding, so that more funders and investees can take advantage of this opportunity and support our call for a European level playing field.

\section{RESEARCH}

$\rightarrow$ Provide data and benchmarking with care and transparency if the industry is to prosper through competition and innovation.

$\rightarrow$ Assist universities and third-party researchers in the collection and understanding of available data, cost of data provision and value of data.

$\rightarrow$ Promote transparency and cooperation among entrepreneurs, crowdfunding platform operators, and funders to keep data open and attainable. The industry will dedicate itself to innovation and will facilitate access to and the sharing of information.

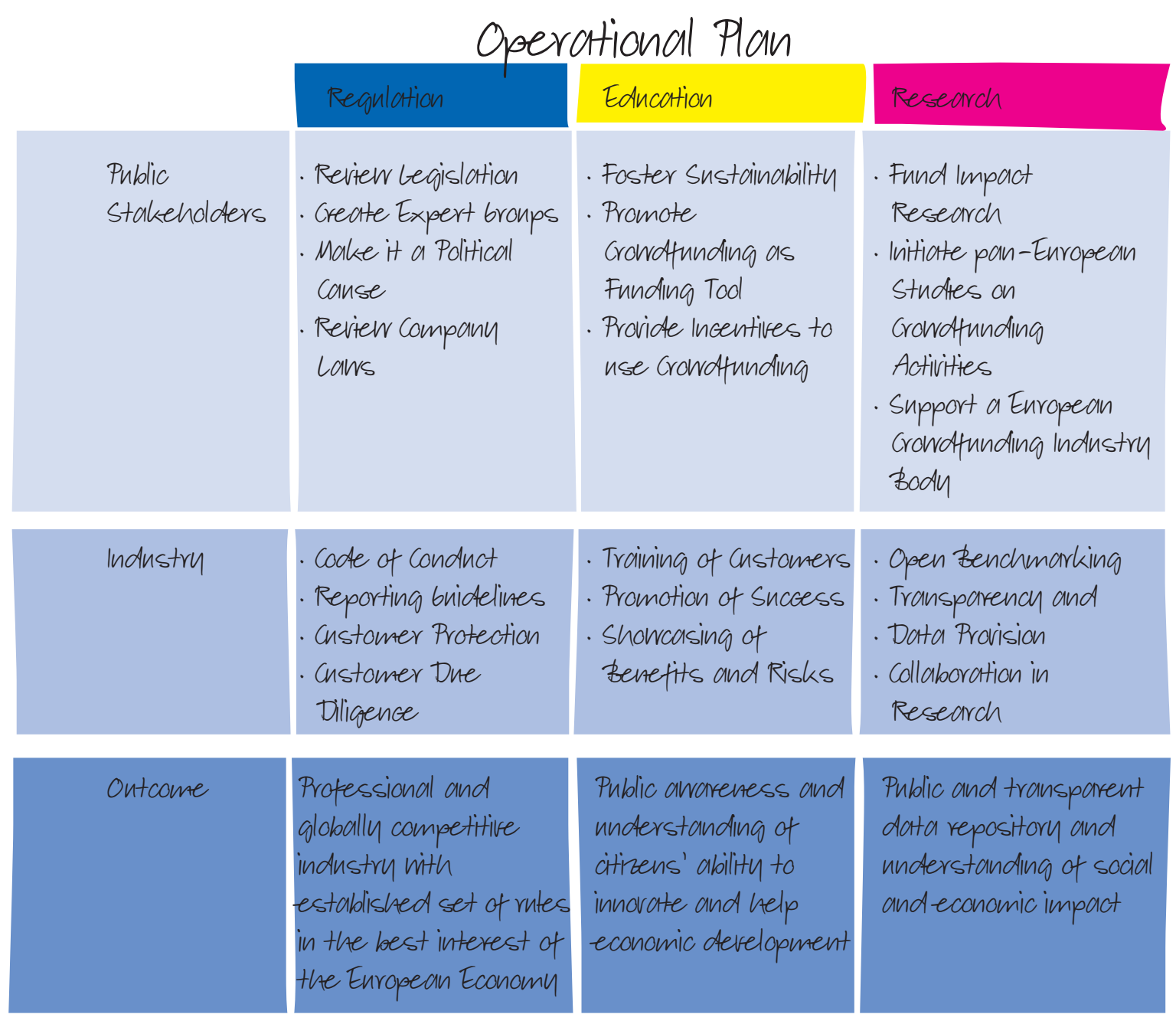




\section{FURTHER READING}

\section{BIBLIOGRAPHY}

Bates Wells \&t Braithwaite (2012): Ten Reforms to Grow the Social Investment Market.

Best, J., Neiss, S. and Jones, D. (2012): How Crowdfund Investing Helps Solve Three Pressing Socioeconomic Challenges.

Bielsko-Biala Declaration: Realising the full potential of crowdfunding initiatives (2011).

Collins, L. and Pierrakis, Y. (2012): The Venture Crowd. Crowdfunding Equity investment into Business.

Clarke, A. (2012): Report of the Chairman of the expert group on the cross border matching of innovative firms with suitable investors.

De Buysere, K. (unpublished): Venture Capital 2.0: Obstacles in using the internet for equity raise campaigns.

Eurada (2012): Scoping Paper - Crowdfunding Meeting. Meeting hosted by the European Economic and Social Committee on 7 June 2012.

Gerven, D. (2009). Prospectus for the public offering of securities in Europe set: European and national legislation in the member states of the European economic area. Cambridge: Cambridge University Press.

Hemer, J. (2011): A snapshot on crowdfunding.

JOBS Act 2012 - Title III - Crowdfunding

Lawton, K. and Marom, D. (2010): The CrowdFunding Revolution.

Zandvliet K. (2012): Lessons learned managing a crowdfunding network. (presentation)

FinPart (2012): Livre Blanc - Finance Participative, Plaidoyer et propositions pour un nouveau cadre réglementaire.

Massolutions (2012): Crowdfunding Industry Report

Neiss, S. and Best, J. (2012). Why the Jobs Act is a Win for Entrepreneur's and Investors, Inc., March 28, 2012.

Nesme, Y. (2012): Crowdfunding: An international comparison and analysis of the constraints and opportunities for implementing it in Portugal.

Opinion of the European Economic and Social Committee on the Communication from the Commission to the Council, to the European Parliament, to the Committee of the Regions, and to the European Economic and Social Committee - An action plan to improve access to finance for SMEs COM(2011) 870 final (2012).

Pereira, P. (2012): Crowdfunding: A new fashion or a real added-value support service for entrepreneurs? (presentation).

Pereira, P. (2012): The Role of Crowdfunding in Promoting Entrepreneurship. 
Crowd-Funding-For-Europe (2012): Proposal for Crowdfunding Amendments to the Prospectuc Directive.

Risterucci, F. (2012): Un nouveau modèle de croissance possible en France. LesEchos.fr

Rubin, S. (2012): The Case for Crowdfunding, Inc. April 17, 2012.

Schammo, P. (2011): EU prospectus law: New perspectives on regulatory competition in securities markets. Cambridge: Cambridge University Press.

Telesca, L. (2012): Crowdfunding challenges and opportunities (presentation).

UKIE Crowd Funding Report (2012): A proposal to facilitate Crowdfunding in the UK.

\section{EUROPEAN COMMISSION COMMUNICATIONS}

Communication from the Commission to the Council, to the European Parliament, to the Committee of the Regions, and to the European Economic and Social Committee. An action plan to improve access to finance for SMEs. \{SEC(2011) 1527 final\}.

Commission staff working paper. Accompanying the document: "Communication from the Commission to the Council, to the European Parliament, to the Committee of the Regions, and to the European Economic and Social Committee. An action plan to improve access to finance for SMEs." $\{$ Com(2011) 870 final\}.

Directive 2003/71/EC of the European Parliament and of the Council of 4 November 2003 on the prospectus to be published when securities are offered to the public or admitted to trading and amending Directive 2001/34/EC.

Directive 2004/39/EC of the European Parliament and of the Council of 21 April 2004 on markets in financial instruments amending Council Directives 85/611/EEC and 93/6/EEC and Directive 2000/12/EC of the European Parliament and of the Council and repealing Council Directive 93/22/EEC.

Directive 2006/48/EC of the European Parliament and of the Council of 14 June 2006 relating to the taking up and pursuit of the business of credit institutions.

Directive 2009/65/EC of the European Parliament and of the Council of 13 July 2009 on the coordination of laws, regulations and administrative provisions relating to undertakings for collective investment in transferable securities (UCITS) (recast of the Directive 85/611/EEC).

Directive 2009/110/EC of the European Parliament and of the Council of 16 September 2009 on the taking up, pursuit and prudential supervision of the business of electronic money institutions amending Directives 2005/60/EC and 2006/48/EC and repealing Directive 2000/46/EC.

Directive 2010/73/EU of the European Parliament and of the Council of 24 November 2010 amending Directives 2003/71/EC on the prospectus to be published when securities are offered to the public or admitted to trading and 2004/109/EC on the harmonisation of transparency requirements in relation to information about issuers whose securities are admitted to trading on a regulated market.

Directive 2011/61/EU of the European Parliament and of the Council of 8 June 2011 on Alternative Investment Fund Managers and amending Directives 2003/41/EC and 2009/65/EC and Regulations (EC) No 1060/2009 and (EU) No 1095/2010.

Proposal for a directive of the European Parliament and of the Council of on markets in financial instruments repealing Directive 2004/39/EC of the European Parliament and of the Council (Recast). 


\section{About the Author}

\section{Kristof De Buysere (Belgium)}

Kristof lectures Business Law to undergraduate students in International Business Administration at Tilburg University, where he also undertakes PhD research. Besides academia, he uses cross-disciplinary skills while he passionately assists early stage to pre-IPO technology companies in their financing steps. He holds a Master's degree in Applied Science and Engineering (Applied Computer Science, Vrije University Brussel), a Graduate Diploma in Finance (University of London - academic direction: LSE), and a Master's degree in Law (Ghent University). He took extracurricular courses (including at Harvard University) in finance, economics, international taxation, chemistry and biotechnology.

\section{Oliver Gajda (Germany)}

is a former business consultant, journalist as well as start-up and buyout manager. He co-founded the European Crowdfunding Network and is acting Co-Chair. During his career Oliver worked with venture capital, microfinance, technology and social entrepreneurship in commercial, non-profit and trade association settings in Europe and the USA. Oliver started his career in the early 1990s in the publishing and market research industries. He holds Masters degrees from Solvay Business School at the Université libre de Bruxelles and from the University of Hamburg; he also studied at SEESS, University College London, in London.

\section{Ronald Kleverlaan (The Netherlands)}

is an international speaker and writer about crowdfunding and co-founder of WEBclusive, the leading crowdfunding software company in Europe. Their software raised millions of euros for more then 500 successful crowdfunding campaigns. He founded the Dutch Crowdfunding Roundtable and is co-founder of the European Crowdfunding Network. He holds Masters degrees from the Asia-Europe Institute at University Malaya in Kuala Lumpur and the University of Amsterdam.

\section{Dan Marom (ISRael)}

is an acclaimed author in the crowdfunding field. In 2010, he co-authored a pioneering book on crowdfunding titled The CrowdFunding Revolution (with Kevin Lawton). A second edition is forthcoming in late 2012 by McGraw-Hill. As a Ph.D. candidate in Finance at the Hebrew University of Jerusalem, Israel, Dan's research focuses on crowdfunding and entrepreneurial finance. Dan has been highly engaged in various REtD and management assignments for several years as a technologist and Founder \& CEO of a start-up company. He currently serves as a strategic consultant to some of the leading Israeli companies and public organizations. Living in Tel Aviv, Israel, Dan holds a Masters in Business Administration (Cum Laude), and a Bachelor of Science in Electrical Engineering.

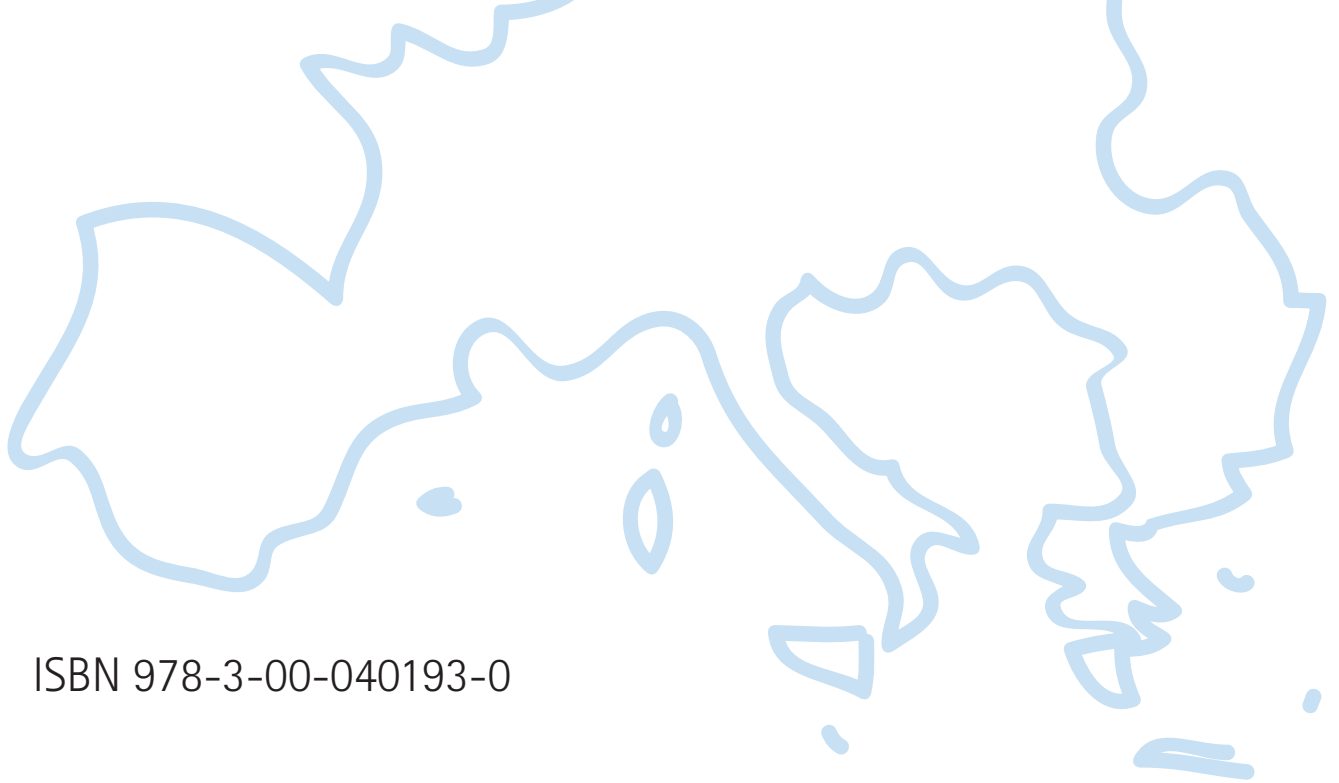

